\title{
The Seismogenic Thickness of the Southern California Crust
}

\author{
by Julie J. Nazareth and Egill Hauksson
}

\begin{abstract}
The average seismogenic thickness, measured from the surface down to maximum depth of earthquake rupture, for the southern California crust is $15.0 \mathrm{~km}$ $(+1.2 /-1.1 \mathrm{~km})$. We determine the seismogenic thickness using the depth distribution of the seismic moment release of $\sim 19$ years of seismicity. We calibrate the depth distribution of moment release from background seismicity by comparing the maximum depth of rupture during moderate- to large-magnitude earthquakes to the premainshock background seismicity of the respective mainshock region. The calibration shows that the depth above which $99.9 \%$ of the moment release of background seismicity occurs reliably estimates the maximum depth of rupture during moderate to large earthquakes. Locally, the seismogenic thickness is highly variable, ranging from less than $10 \mathrm{~km}$ in the Salton Trough to greater than $25 \mathrm{~km}$ at the southwestern edge of the San Joaquin Valley. Similarly, the seismogenic thickness along the major strike-slip faults can vary significantly along strike. Changes in seismogenic thickness along strike do not correspond to the mapped surface segmentation of the major southern California strike-slip fault systems. In the future, such estimates of the seismogenic thickness can be used to refine existing seismichazard estimates for southern California.
\end{abstract}

\section{Introduction}

The Pacific-North America plate boundary forms a broad zone of deformation extending across southern California and into the Continental Borderland (Fig. 1). In this study we determine the seismogenic thickness of this zone in a systematic fashion, using the depth distribution of earthquakes. To determine seismogenic thickness from focal depths of background seismicity, the depth distribution of moment release of the background seismicity is calibrated using the maximum depth of finite rupture for moderate to large earthquakes. Our study compliments the study by Peterson et al. (1996), who used along-fault projections of hypocenters to visually estimate the down-dip width of major faults.

Improved knowledge of the seismogenic thickness or depth of faulting will improve future seismic hazard estimates for southern California. The seismogenic thickness can be used to calculate the down-dip width of faulting and thus improve the estimate of the realistic rupture area for a given fault. An improved estimate of the potential rupture area will reduce uncertainties in potential moment release and thus contribute to more accurate seismic hazard estimates.

In a previous study, Magistrale and Zhou (1996) compared the depth extent of background seismicity with that of the aftershock zone (as proxy for maximum depth of mainshock rupture) of major earthquakes in southern California, and they concluded that the depth extent of rupture during future earthquakes could be determined from the background seismicity. Other studies in California have linked the depth of hypocenters to physical factors that affect crustal rheology (Doser and Kanamori, 1986; Sanders, 1987; Miller and Furlong, 1988; Hill et al., 1990; Sanders, 1990; Magistrale and Zhou, 1996; Williams, 1996). We take the next step and use both the background seismicity and finitesource models from large earthquakes to predict the seismogenic thickness or the brittle behavior of the crust across the whole region.

Data

Our dataset consists of 257,918 selected earthquakes recorded by the Southern California Seismic Network (SCSN), a cooperative project of Caltech and U.S. Geological Survey, between April 1981 and July 2000 and it ranges in magnitude from 0.1 to 7.3 (Fig. 2). These earthquakes have been relocated using the 3D velocity model of Hauksson (2000), so that biases caused by the effects of 3D crustal structure are minimized. This earthquake dataset represents a significant improvement over the seismic network catalog, which is located using a $1 \mathrm{D}$ velocity model, and other previous relocated catalogs covering limited areas.

We use the formal errors calculated during the relocation of the hypocenters to establish selection criteria. These formal errors account for phase-pick errors, azimuthal cov- 


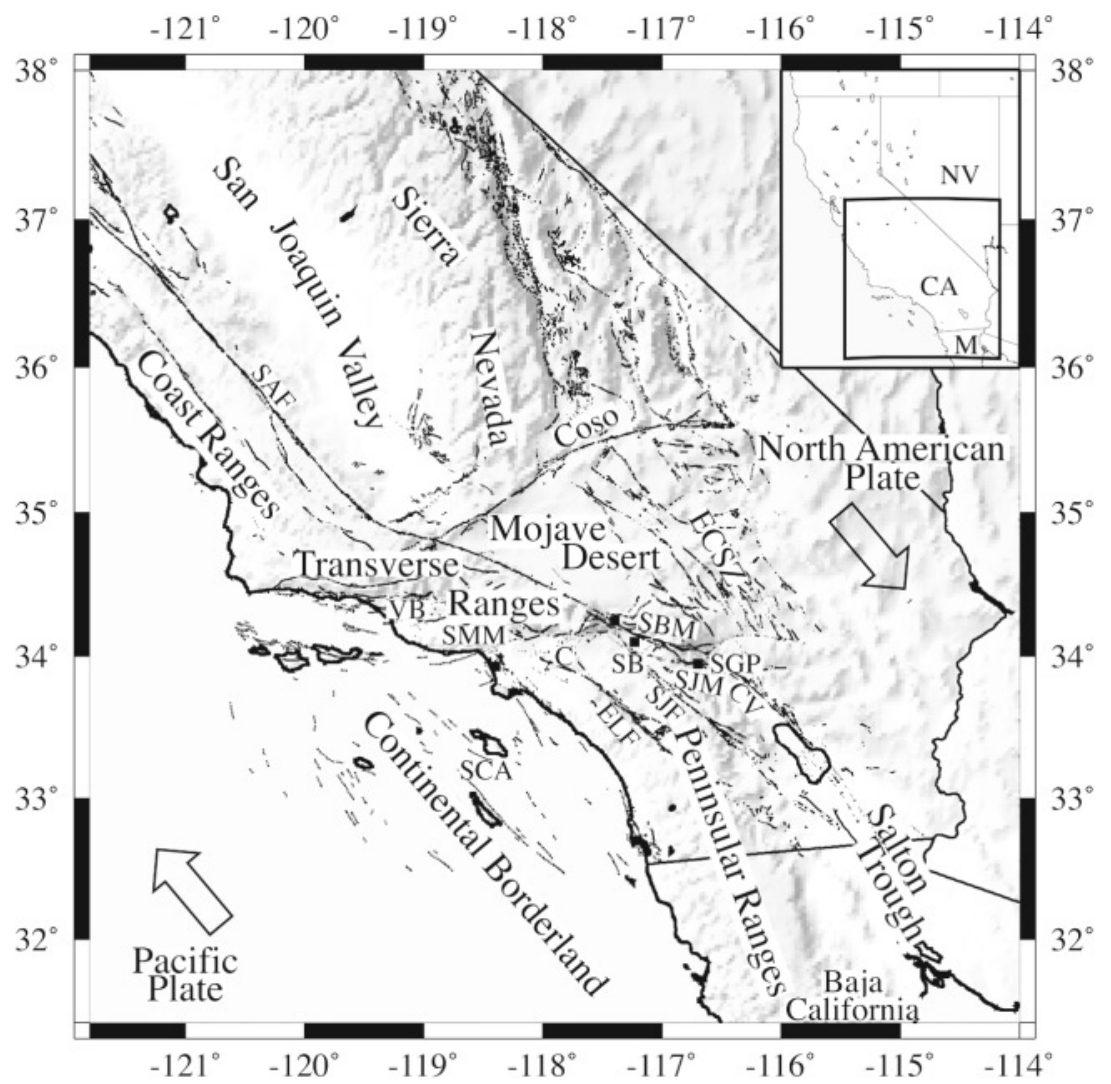

Figure 1. Tectonic and physiographic provinces of southern California in study area. Mapped surface traces of faults (Jennings, 1975) shown as thin black lines. The arrows show the approximate relative motion of the Pacific and North American plates. C, ChinoPuente Hills; CA, state of California; CV, Coachella Valley; ECSZ, Eastern California Shear Zone; NV, state of Nevada; M, Mexico; SB, San Bernardino (city); SBM, San Bernardino Mountains; SCA, Santa Catalina Island; SGP, San Gorgonio Pass; SJM, San Jacinto Mountains; SMM, Santa Monica Mountains; VB, Ventura Basin. erage, and the distance to the nearest station, but they do not account for unresolved small-scale $(<15 \mathrm{~km})$ heterogeneity in the velocity structure. We rejected 75,167 events from the initial dataset of 333,085 earthquakes because they did not satisfy one or more of the following criteria: (1) the hypocenter must be vertically constrained; (2) vertical error in the location of the hypocenter must be equal to or less than 2.0 $\mathrm{km}$; (3) the horizontal error of the hypocenter cannot exceed $1.5 \mathrm{~km}$; (4) the earthquake must be recorded by at least 10 stations, unless the distance to the nearest station is less than twice the depth of the hypocenter; (5) a magnitude must be available in the Caltech/U.S. Geological Survey (USGS) catalog. The allowed vertical error is larger than the horizontal error to allow for better spatial coverage in our dataset. Although we allow earthquakes to have horizontal and vertical errors up to 1.5 and $2.0 \mathrm{~km}$, respectively, $86 \%$ of the earthquakes have horizontal errors less than or equal to $0.5 \mathrm{~km}$, and $87 \%$ of the earthquakes have vertical errors less than or equal to $1.0 \mathrm{~km}$ (Fig. 3). Seventy-one percent of the earthquakes have 10-30 observations, but a single event may have as great as 255 or as few as four observations. We assume an earthquake can still be well located with fewer than 10 observations, if the earthquake occurred close to one seismic station.

In addition to hypocenter and magnitude information, we have focal mechanisms for 74,774 earthquakes in our dataset (Hauksson, 2000). This allows us to include the effect of dip on the depth distribution of moment of the earth- quake. For smaller-magnitude earthquakes, the dip of the fault plane has little effect on the depth distribution of moment because of the small size of the fault planes. However, for larger earthquakes (i.e., those that contain a large portion of the moment release in a region), fault-plane dip can have a significant effect by controlling the proportion of the depth column in which a significant amount of seismic moment was released. The earthquakes without focal-mechanism information are assumed to have vertical rupture planes.

\section{Method and Results}

We define the maximum depth of rupture to be the depth above which the vast majority of the moment release (or hypocenters) within a depth column occurs. The term "vast majority" is not easy to define. Previous studies have used the depth above which a certain percentage of hypocenters lie (e.g., 90\%, Miller and Furlong, 1988; 95\%, Williams, 1996). These studies offer no simple justification for the choice of these percentages, and it is unclear what this depth means in terms of brittle failure. In this study, we equate the maximum depth of rupture with the percent depth, the depth above which a quantitatively determined percentage of moment release occurs. We establish the appropriate percentage of moment release for southern California and compare the use of moment release versus hypocenters. 


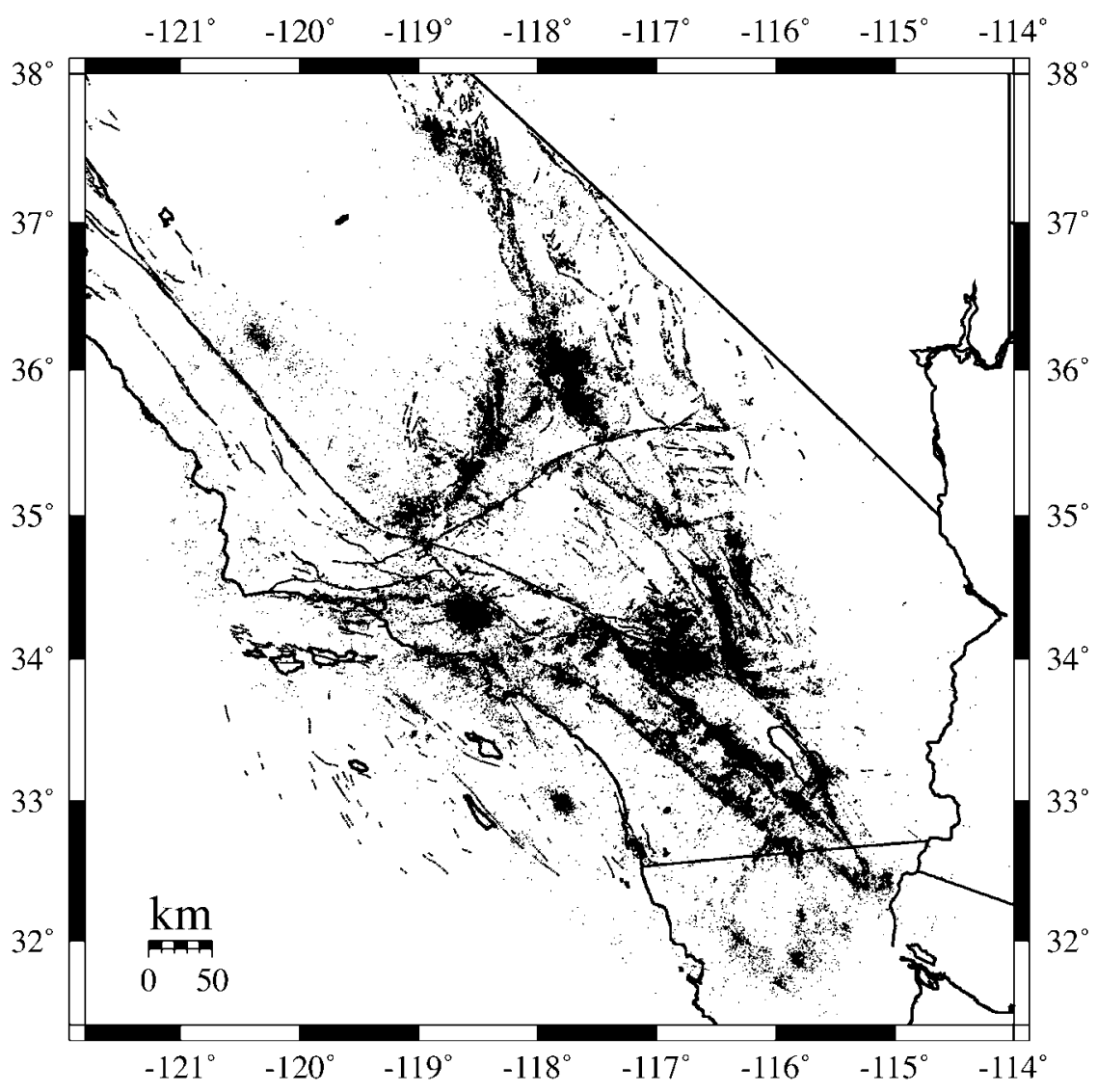

Figure 2. Earthquakes used in this study. Mapped surface traces of faults (Jennings, 1975) shown as thin black lines.

Comparison of Finite-Source Models to Premainshock Regional Seismicity

We use published finite-source models to calibrate regional seismicity as a predictor of maximum rupture depth during moderate to large earthquakes. These models are most likely to accurately estimate the true fault dimensions of larger earthquakes because they are constructed from data that is directly attributable to the earthquake in question (e.g., strong-motion seismic data, teleseismic waveforms, and, to some extent, geodetic data). Using more indirect evidence (e.g., aftershock distribution) or spatially limited data (e.g., length of any surface rupture) to estimate rupture size can be problematic because different results can occur depending on the evidence used (Wells and Coppersmith, 1994). Because aftershocks occur in the same overall rheological environment as the mainshock, they seem to be a response to the mainshock rupture and reflect the rupture of the crust during the mainshock reasonably well (Wells and Coppersmith, 1994).

During the regional seismicity calibration, we determine the appropriate value of percent depth for southern California and estimate the range in this value caused by uncertainties in the data. We compare 16 distinct finite-source models for nine moderate to large earthquakes in southern California
(Table A1) to the premainshock seismicity of the mainshock region. The mainshock region is based on the regional extent of the first $24 \mathrm{hr}$ of aftershocks. Details regarding the slip models used for the calibration can be found in the Appendix.

To determine the appropriate value of percent depth, we pose a simple test for the premainshock regional seismicity. What percent of total moment release or of total number of hypocenters within the defined region are shallower or depth equal to the bottom of the finite-source model in question? This is a simple test for earthquake hypocenters because, regardless of magnitude, as points in space, the hypocenters can be put in increasing depth order and counted. The twodimensional nature of moment release requires us to sort the moment release of various magnitude earthquakes, and therefore various rupture areas, into depth bins. These depth bins correspond to the depth ranges of the subfaults that make up a finite-source model.

In the next sections, we examine depth distribution of both hypocenters and moment release of the regional seismicity to show that the depth distribution of regional premainshock seismicity provides a reasonable estimation of the maximum depth of rupture during the moderate- to largemagnitude mainshock. Although preliminary aftershock dis- 

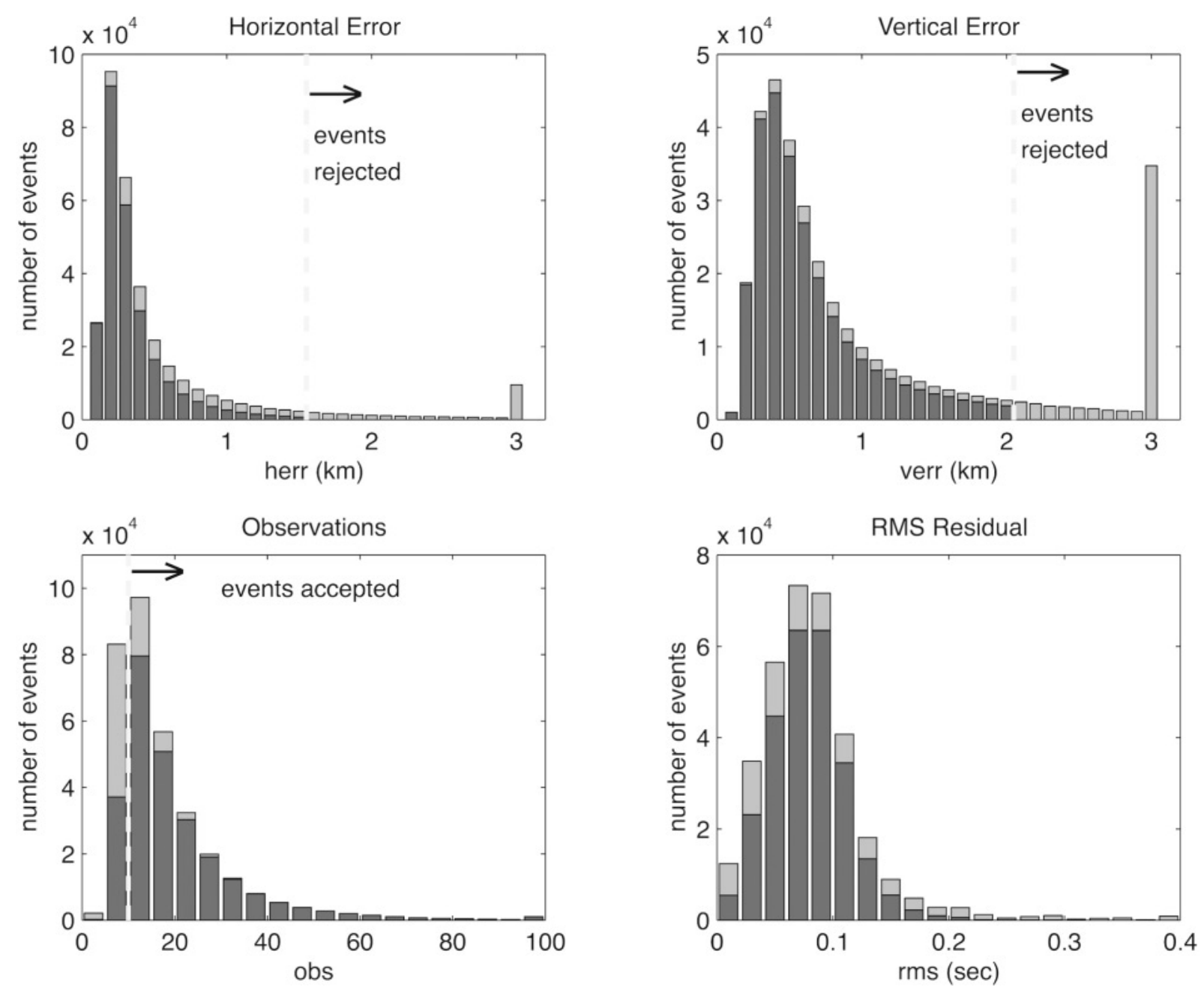

Figure 3. Errors in the full earthquake dataset. Events with acceptable errors and sufficient observations are represented by the black columns (257,918 earthquakes). The white regions represent the errors of the 75,167 earthquakes rejected because of one or more unacceptable errors. The dashed lines show the division between acceptable and unacceptable values. Some events are considered acceptable with less than ten observations if the distance to the nearest seismic station is less than twice the depth. rms was not used as a sorting criterion. The bar farthest to the right represents all events equal or greater than the bin value, and thus it may appear much larger than the surrounding bins.

tributions are often used to design starting geometries for finite-source models, the finite-source models are allowed to determine their own geometry and slip distribution using an iterative approach (Wald et al., 1996). We test which method of earthquake representation is a better predictor of the maximum depth of rupture during moderate to large earthquakes. Finally, assuming that the maximum depth extent of rupture during a moderate to large earthquake in southern California is synonymous with the seismogenic thickness of the region, we calculate the appropriate value of percent depth to use when estimating the seismogenic thickness of southern California.

Moment Release Distribution Test. We first consider the depth distribution of moment release as a predictor of the maximum depth of rupture during moderate to large southern California earthquakes. The percent of total moment released by the background seismicity shallower than the bottom of the finite source model rupture planes was greater than $99.7 \%$ for 14 of the 16 reference models (Fig. 4 a). The two exceptions are NPS and N-HU. In addition, we have excluded the reference models WN and SM because the premainshock background seismicity was extremely sparse ( $\leq$ eight earthquakes) and, therefore, the result was unreliable. These four slip models were excluded from our calculation of the appropriate value of moment percent for the prediction of seismogenic thickness in southern California (see Appendix for discussion of excluded models). The 12 models used to calculate the appropriate percent value for the estimation of seismogenic thickness are ER, SH-W, SH-L, JT-B, JT- 


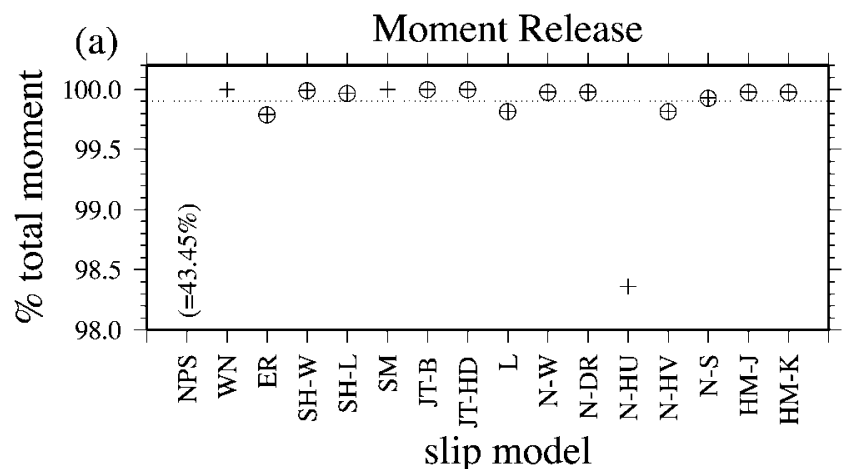

(b)

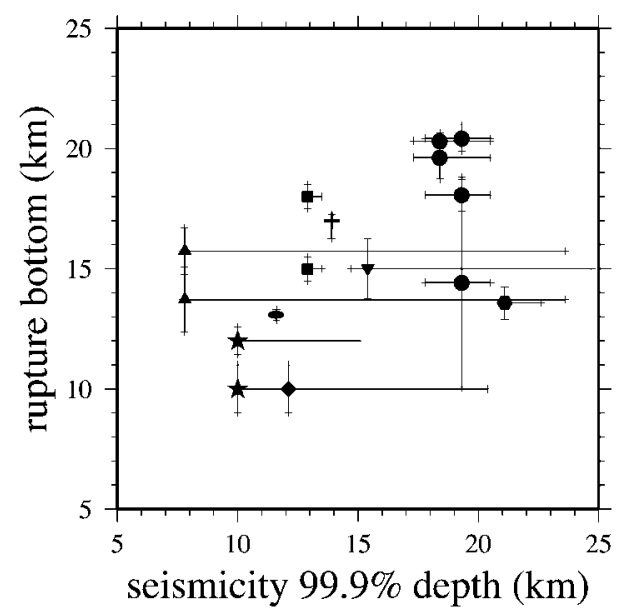

Figure 4. (a) Percent of total moment release of premainshock seismicity that occurred shallower or equal to the rupture bottom of the slip model (see Table A1 for slip-model references). Circled data points are the values used to calculate the percent depth for southern California ( $\%=99.9$; shown as a dotted line). (b) The $99.9 \%$ depth of the premainshock seismicity versus the rupture bottom of the slip model. If the prediction were perfect, the two values would be equal. Horizontal error bars indicate the percent depths for $99.8 \%$ and $99.99 \%$ ( \pm one standard deviation). Fewer earthquakes occur at depths approaching the maximum depth, so a small change in percent of total moment results in a large change in percent depth. Vertical error bars indicate one-half the width of the slip model subfaults. Slip-model symbols: NPS, hexagon; WN, cross; ER, diamond; SH, star; SM, ellipse; JT, square; L, inverted triangle; N, circle; HM, triangle.

HD, L, N-W, N-DR, N-HV, N-S, HM-J, and HM-K. The mean percent of background seismicity moment release shallower than the bottom of the mainshock rupture plane is $99.9 \%( \pm 0.1 \%)$.

This test is not complete, however, without considering the effect of known errors and assumptions: (1) the vertical error of the hypocenter; (2) the distribution of moment release about the hypocenter; and (3) the definition of the 24$\mathrm{hr}$ aftershock zone. We consider the effects of error/assumption 1 and 2 by looking at the shallow and deep extremes in distributing the moment release. The difference in percent moment shallower than the bottom of the slip model between the shallow and deep error extremes is often less than $0.1 \%$. When the difference is greater, the extreme moment release distributions, which show that the background seismicity dataset includes one or a few earthquakes that contain a significant proportion of the total moment release of the region, are modeled with large uncertainty (e.g., model SH-L). When these earthquakes are located deeper in the crust, the uncertainty in distributing the moment release about the hypocenter significantly changes the distribution of moment release near the bottom of the slip model. We investigated the effect of error/assumption 3 by considering both "tight" and "loose" interpretations of the aftershock zone and found little difference in the results of the test.

The consistency of the estimate of the percent of background seismicity moment release shallower than the bottom of the rupture planes of moderate to large earthquakes for the southern California earthquakes tested above, and the very small difference between the shallow and deep distribution extremes, suggests that the distribution of moment release of regional seismicity is an accurate and stable estimator of the seismogenic thickness of the region. The accuracy of the technique can be evaluated qualitatively by comparing the predicted depth extent with the rupture bottom of the slip models (Fig. 4b). If the prediction were perfect, the two depths would be identical. Part of the inaccuracy seen in the plot arises from errors and differences in the slip models. The relationship can also be tested quantitatively using a Student's $t$-Test for paired data. The calculated correlation coefficient for total moment release of the 99.9\% depth of the premainshock seismicity and the rupture bottom of the slip models (Fig. 4b) was 0.54 , with a corresponding correlation probability 0.03 , thus demonstrating that the two variables are significantly correlated. Overall, the moment release percent depth predicts the maximum rupture depth of moderate to large earthquakes very well.

Hypocenter Distribution Test. We now consider the distribution of hypocenters as a predictor of the depth extent of rupture for moderate to large earthquakes. The percent of background seismicity hypocenters shallower than the bottom of the finite-source model rupture planes was greater than $94 \%$ for 15 of the 16 reference models (Fig. 5a). The exception, model NPS, had a much lower percentage than the other models, because the earthquake occurred along a step in the maximum depth in seismicity (discussed in the Appendix as an excluded model). As in the moment release distribution test, we have excluded reference models NPS, $\mathrm{N}-\mathrm{HU}, \mathrm{WN}$, and SM. The 12 models used to calculate the appropriate percent value for the estimation of seismogenic thickness are ER, SH-W, SH-L, JT-B, JT-HD, L, N-W, NDR, N-HV, N-S, HM-J, and HM-K. The mean percent of background seismicity hypocenters shallower than the bottom of the mainshock rupture plane is $98.3 \%( \pm 1.8 \%)$.

Unlike the extreme limits in the moment distribution calculation, the extreme limits for the hypocenter test are 


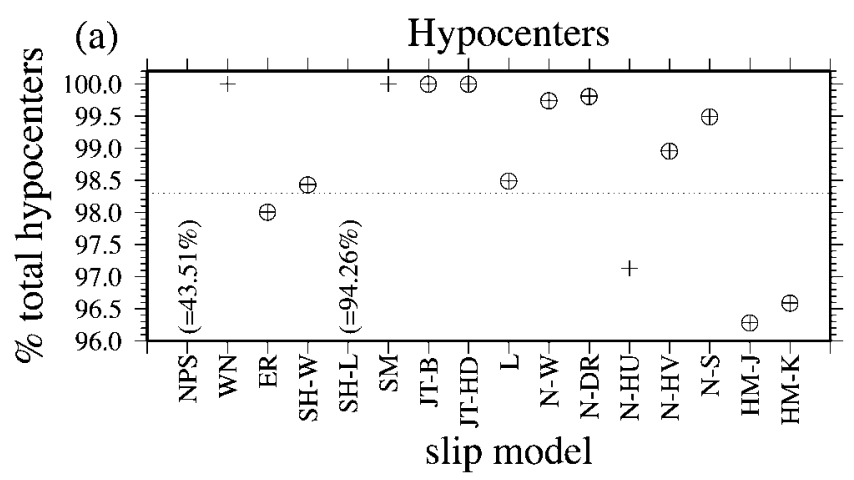

(b)

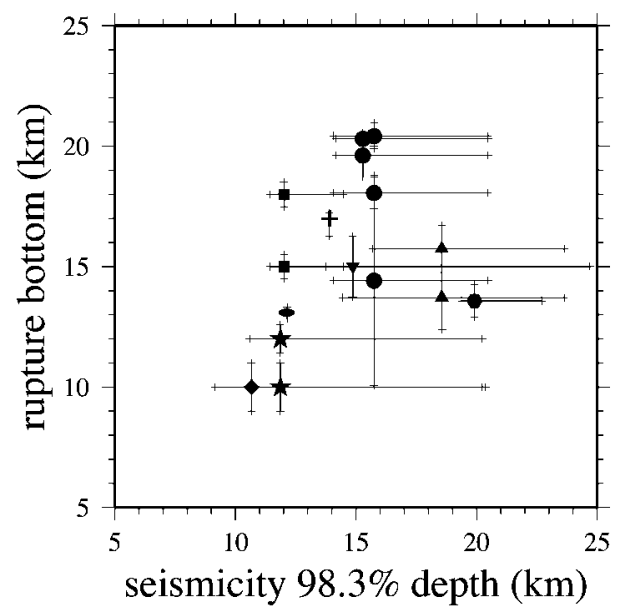

Figure 5. (a) Percent of total hypocenters of premainshock seismicity that occurred shallower or equal to the rupture bottom of the slip model (see Table A1 for slip-model references). Circled data points are the values used to calculate the percent depth for southern California $(\%=98.3$; shown as a dotted line). (b) The $98.3 \%$ depth of the premainshock seismicity versus the rupture bottom of the slip model. If the prediction were perfect, the two values would be equal. Horizontal error bars indicate the percent depths for $96.5 \%$ and $100 \%$ ( \pm one standard deviation). Fewer earthquakes occur at depths approaching the maximum depth, so a small change in percent of total hypocenters results in a large change in percent depth. Vertical error bars indicate one-half the width of the slip-model subfaults. Slip-model symbols: NPS, hexagon; WN, cross; ER, diamond; SH, star; SM, ellipse; JT, square; L, inverted triangle; $\mathrm{N}$, circle; $\mathrm{HM}$, triangle.

only based on the vertical error in the hypocenter. The difference in percent of hypocenters shallower than the bottom of the slip model between the shallow and deep error extremes ranges is $2 \%$ on average, one order of magnitude greater than the range for the moment distribution test. This larger range cannot be attributed solely to the smallest allowable step in percentage defined by the percentage of the total number contained in one hypocenter (see Appendix for discussion). We believe the larger range in error extremes is in part caused by the imprecision of using the hypocenter to represent the rupture of earthquakes regardless of magnitude and rupture area.

The estimate of the percent of background seismicity hypocenters shallower than the bottom of the rupture planes tested previously is not as consistent as that of moment release. Accuracy and stability suffer as a result. The predicted rupture depth extent from hypocenters is compared with the rupture bottom of the slip models in Figure 5b. As in Figure $4 \mathrm{~b}$, if the prediction were perfect, the two depths would be identical and fall on a line with slope of 1 . The predictions are more varied and, in general, fall much further from the perfect prediction line than the moment release predictions. Qualitatively, the percent depth of hypocenters provides a fair prediction of the seismogenic thickness. The same cannot be said of a quantitative comparison of the relationship. The calculated correlation coefficient for the $98.3 \%$ depth of the premainshock seismicity and the rupture bottom of the slip model (Fig. 5b) was 0.31 with corresponding correlation probability 0.23 , hence, exhibiting insignificant correlation. This difference in the correlation coefficient between the hypocenters and total seismic moment release of premainshock seismicity demonstrates that the total moment release is a more stable measure of seismogenic thickness than the focal depths of individual hypocenters.

Moment Release versus Hypocenters for Estimating the Seismogenic Thickness. We have shown that the percent of background seismicity moment release and hypocenters shallower than the bottom of the mainshock rupture plane is consistent for a number of moderate to large earthquakes in southern California during the past 20 years. This analysis has shown that background seismicity in the region of the future mainshock predicts the maximum depth extent of rupture during the mainshock. Although the distribution of hypocenters reasonably predicts the maximum depth qualitatively, the percent results for moment release have less variation, have smaller error extremes, and are more accurate and precise because the rupture extent of the background seismicity is taken into account. Further, the finite-rupture extent of all earthquakes provides some smoothing as opposed to scattered point measurements provided by individual hypocenters. We now have a quantitatively estimated value to apply to the background seismicity to predict the seismogenic thickness for all of southern California.

\section{Regional Predictions of Seismogenic Thickness for Southern California}

To provide a comprehensive overview of the variations in the seismogenic thickness across southern California, we divide the region into $0.1^{\circ} \times 0.1^{\circ} 2 \mathrm{D}$ bins ("regional bins") and calculate the depth distribution of moment release of all earthquakes with epicenters located within each regional bin (Fig. 6). We use finite-source models to represent the moment release for the 12 earthquakes $(M>5)$ marked with an asterisk (*) in Table A3. This allows the moment release 


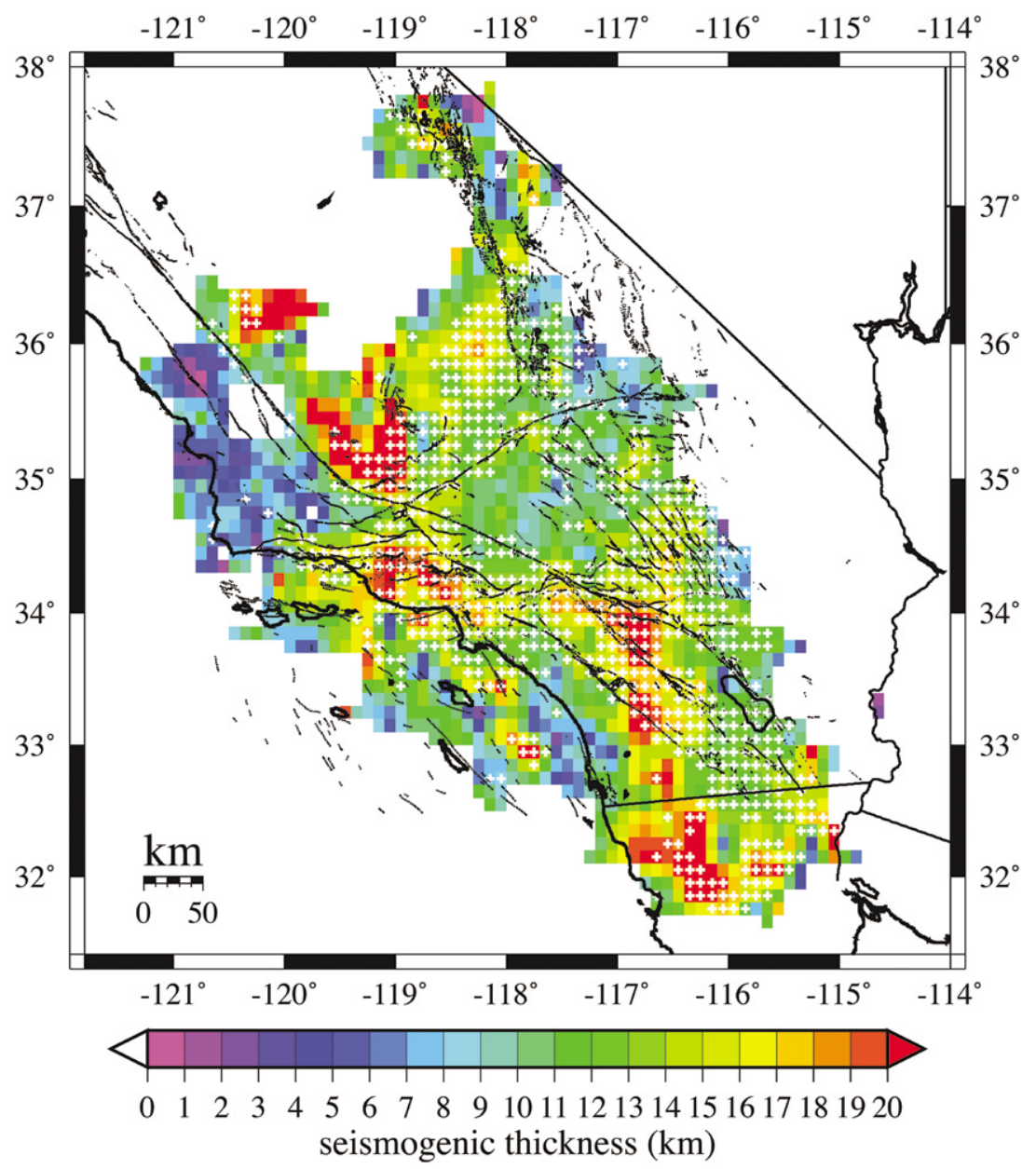

Figure 6. Smoothed seismogenic thickness for all regional bins. A Gaussian filter (length, $30 \mathrm{~km}$ ) has been applied to the seismogenic thickness estimate to improve the spatial coherence of the image. The white crosses mark $0.1^{\circ} \times 0.1^{\circ}$ bins that are considered to have a reliable seismogenic thickness estimate because they contain at least 10 earthquakes. to be distributed across a number of bins, rather than forcing all the moment release into the regional bin where the epicenter is located. For each bin, the seismogenic thickness is defined as the depth above which $99.9 \%$ of the moment release occurs. The moment method provides some inherent smoothing that is not available from estimating the depth distribution of the tail end of a scattered distribution of a few hypocenters. Further, the moment method provides a measure of the distribution of moment release, as opposed to hypocenters that provide the distribution of points of initiation of rupture.

We estimate the error range in this prediction by calculating the difference between the shallow and deep moment release distribution extremes (see Appendix for discussion). On average, the error range in the seismogenic thickness predictions is $2.3 \mathrm{~km}$, or $+1.2 /-1.1 \mathrm{~km}$. The average error decreases as the number of earthquakes per regional bin increases. Bins on the edge of southern California tend to have a much larger error range than those in the center. Individual bins may have larger or smaller error ranges depending on the distribution of earthquakes with depth within the regional bin. A large difference between moment release distribution extremes is usually due to larger earthquakes $(M>5)$ without finite-source slip models or earthquakes with large vertical errors near the base of the moment release distribution.

The more than 258,000 earthquakes in our dataset are located in 1823 regional bins covering approximately $70 \%$ of the land area of southern California below N36 latitude (excluding the Continental Borderland and Baja California). Approximately $54 \%$ of the regional bins with data contain less than ten earthquakes. Most of these bins are located on the edge of the study area, in the deserts of eastern California, the western Peninsular Ranges, the western Mojave Desert, the Coast Ranges, and the Continental Borderland. These regions tend to have few mapped faults and/or are on the fringes of the SCSN where fewer earthquakes can be accurately identified and relocated. As a result, the estimate of seismogenic thickness in these regions produces a mostly incoherent checkerboard pattern. Therefore, the seismogenic thickness prediction is considered unreliable in regions with few earthquakes (here taken to be less than ten earthquakes per regional bin), as well as regions beyond the seismic network (e.g., the Continental Borderland outboard of Santa Catalina Island and south of the international border in Baja California).

The seismogenic thickness of southern California is highly variable, ranging from less than $10 \mathrm{~km}$ in the Salton 
Trough to greater than $25 \mathrm{~km}$ at the southwestern edge of the San Joaquin Valley (Fig. 6). A gaussian filter (length, 30 $\mathrm{km})$ was applied to the regional seismogenic thickness estimate to improve the spatial coherence. It is important to recognize the areas with reliable seismogenic thickness estimates, because too few earthquakes within a regional bin tend to result in an underestimate of the seismogenic thickness. The areas with the greatest seismogenic thickness predictions $(>20 \mathrm{~km})$ are the Ventura Basin, the San JacintoSan Gorgonio Pass region, the west San Joaquin Valley, northern Baja California (estimate unreliable), and portions of the Eastern California Shear Zone, the Santa Monica Mountains/San Fernando Valley, the San Jacinto fault system, and the Elsinore fault system. Regions with the smallest seismogenic thickness are the Salton Trough and the Coso region. Portions of the Continental Borderland and the Coast Ranges also have small seismogenic thickness although these estimates are less reliable.
Predictions of Seismogenic Thickness for the Major Strike-Slip Fault Systems

The three major strike-slip fault zones in southern California contribute a significant proportion of the seismic hazard to the region. We have quantitatively estimated the down-dip width of the segments of the San Andreas fault zone (Cholame southward), the San Jacinto fault zone, and the Whittier-Elsinore fault zone. We use the fault-segment definitions of the California Division of Mines and Geology (CDMG)/USGS database (Petersen et al., 1996). Fault segments are divided into subsegments based on the straightline segments in the CDMG map definition. The subsegments are named for the whole fault segment and numbered from north to south (Table 1).

The moment release of seismicity within $5 \mathrm{~km}$ of the fault is used to calculate the percent depth. This limits the estimate to earthquakes close to the fault but provides

Table 1

Seismogenic Thickness of Strike-Slip Fault Segments

\begin{tabular}{|c|c|c|c|c|c|c|}
\hline Subsegment no. & CDMG/USGS RB (km) & WSS H (km) & Mean $\mathrm{H}(\mathrm{km})$ & Minimum H (km) & Maximum H (km) & Segment Description \\
\hline \multicolumn{7}{|l|}{ San Andreas } \\
\hline 1 & 12 & 12.8 & 9.1 & 8.2 & 10.2 & Cholame \\
\hline 2 & 12 & 15.4 & 12.1 & 8.7 & 15.4 & Carrizo Plain \\
\hline 3 & & 16.2 & 13.2 & 11.6 & 14.3 & \\
\hline 4 & & 20.7 & 15.6 & 14.8 & 16.1 & \\
\hline 5 & & 19.0 & 16.4 & 15.6 & 17.2 & \\
\hline 6 & & 16.0 & 13.0 & 11.9 & 15.2 & \\
\hline 7 & 12 & 14.2 & 12.4 & 11.8 & 12.9 & Mojave \\
\hline 8 & & 12.1 & 11.5 & 10.1 & 13.5 & \\
\hline 9 & 18 & 22.3 & 17.0 & 14.7 & 21.8 & San Bernardino \\
\hline 10 & & 19.1 & 17.7 & 15.3 & 21.1 & \\
\hline 11 & 12 & 19.4 & 12.9 & 11.2 & 14.9 & Coachella Valley \\
\hline 12 & & 15.0 & 9.7 & 8.3 & 11.0 & \\
\hline \multicolumn{7}{|l|}{ San Jacinto } \\
\hline 13 & 15 & 19.8 & 17.8 & 16.4 & 19.9 & San Bernardino \\
\hline 14 & & 19.0 & 19.7 & & & \\
\hline 15 & 18 & 20.7 & 19.6 & & & San Jacinto Valley \\
\hline 16 & & 18.4 & 18.2 & 17.5 & 19.1 & \\
\hline 17 & 18 & 20.0 & 18.3 & 17.3 & 19.4 & Anza \\
\hline 18 & & 16.3 & 17.1 & 15.3 & 19.0 & \\
\hline 19 & 15 & 16.4 & 16.3 & 13.5 & 19.4 & Coyote Creek \\
\hline 20 & 12 & 13.9 & 12.1 & 11.3 & 12.9 & Borrego \\
\hline 21 & 12 & 12.0 & 11.0 & 10.3 & 11.7 & Superstition Mountain \\
\hline 22 & 12 & 11.9 & 11.4 & 10.7 & 11.9 & Superstition Hills \\
\hline 23 & 12 & 15.6 & 14.5 & 11.2 & 17.8 & Imperial \\
\hline \multicolumn{7}{|l|}{ Elsinore } \\
\hline 24 & 15 & 15.8 & 12.6 & 9.3 & 15.9 & Whittier \\
\hline 25 & 15 & 13.2 & 11.9 & 8.7 & 14.1 & Glen Ivy \\
\hline 26 & 15 & 16.3 & 15.1 & 13.5 & 16.7 & Temecula \\
\hline 27 & 15 & 20.8 & 18.0 & 13.0 & 22.5 & Julian \\
\hline 28 & 15 & 13.7 & 12.5 & 10.2 & 13.8 & Coyote Mountain \\
\hline 29 & 15 & 10.7 & 10.5 & 10.3 & 10.9 & Laguna Salada \\
\hline 30 & & 23.8 & 11.4 & 7.4 & 23.8 & \\
\hline 31 & 15 & 13.7 & 13.7 & 10.3 & 16.4 & Chino-Central Avenue \\
\hline 32 & 15 & 17.3 & 16.4 & 14.2 & 17.4 & Earthquake Valley \\
\hline 33 & & 15.4 & 16.1 & 15.4 & 18.0 & \\
\hline
\end{tabular}

RB, rupture bottom from CDMG/USGS fault database; WSS, whole-subsegment seismogenic thickness estimate; mean, min, and max H, the mean, minimum, and maximum seismogenic thickness estimates for the smoothed 5-km along-strike bins of each fault subsegment. 
enough earthquakes for a reliable seismogenic thickness estimate in most cases. It reduces the overlap in seismicity for subparallel fault segments [e.g., SJF-Anza-2 (subsegment 18) and SJF-Coyote Creek (subsegment 19)], and excludes some fault-parallel seismicity that is not clearly linked to the fault systems in question [e.g., SAF-Coachella-1 (subsegment 11) and seismicity from the 1992 Joshua Tree sequence].

We estimate the seismogenic thickness from the seismicity along each whole CDMG/USGS subsegment and for 5-km along-strike bins. If the last along-strike bin of a subsegment is less than $2.5 \mathrm{~km}$, the seismicity is combined with the previous along-strike bin for the seismogenic thickness estimation. In most cases, the 5-km along-strike bins contain a sufficient seismicity for a reliable prediction. We smooth the seismogenic thickness prediction with a five-point average, including along-strike bins from succeeding subsegments when the subsegments are connected (e.g., the San
Andreas subsegments). The seismogenic thickness estimate from the center bin holds weight equal with the two alongstrike bins from both sides, but along-strike bins with no data are skipped.

The error range in seismogenic thickness prediction on average is $1.7 \mathrm{~km}$, or $+0.8 /-0.9 \mathrm{~km}$. This error is an improvement on the CDMG/USGS error estimate of $\pm 2 \mathrm{~km}$ (Peterson et al., 1996). The average error in seismogenic thickness is similar for all three strike-slip zones.

San Andreas Fault Zone. The rate and depth distribution of the background seismicity within $5 \mathrm{~km}$ of the San Andreas fault, from the northernmost Cholame to the southernmost Coachella Valley segment, varies significantly along the strike of the fault (Fig. 7). Most of the moment release and the deepest seismicity occur at the two ends of the big bend, Tejon Pass and Banning, where the fault changes strike. The Banning-San Gorgonio Pass region (subsegments 9-11) forms the southern end of the big bend. The seismicity ex-

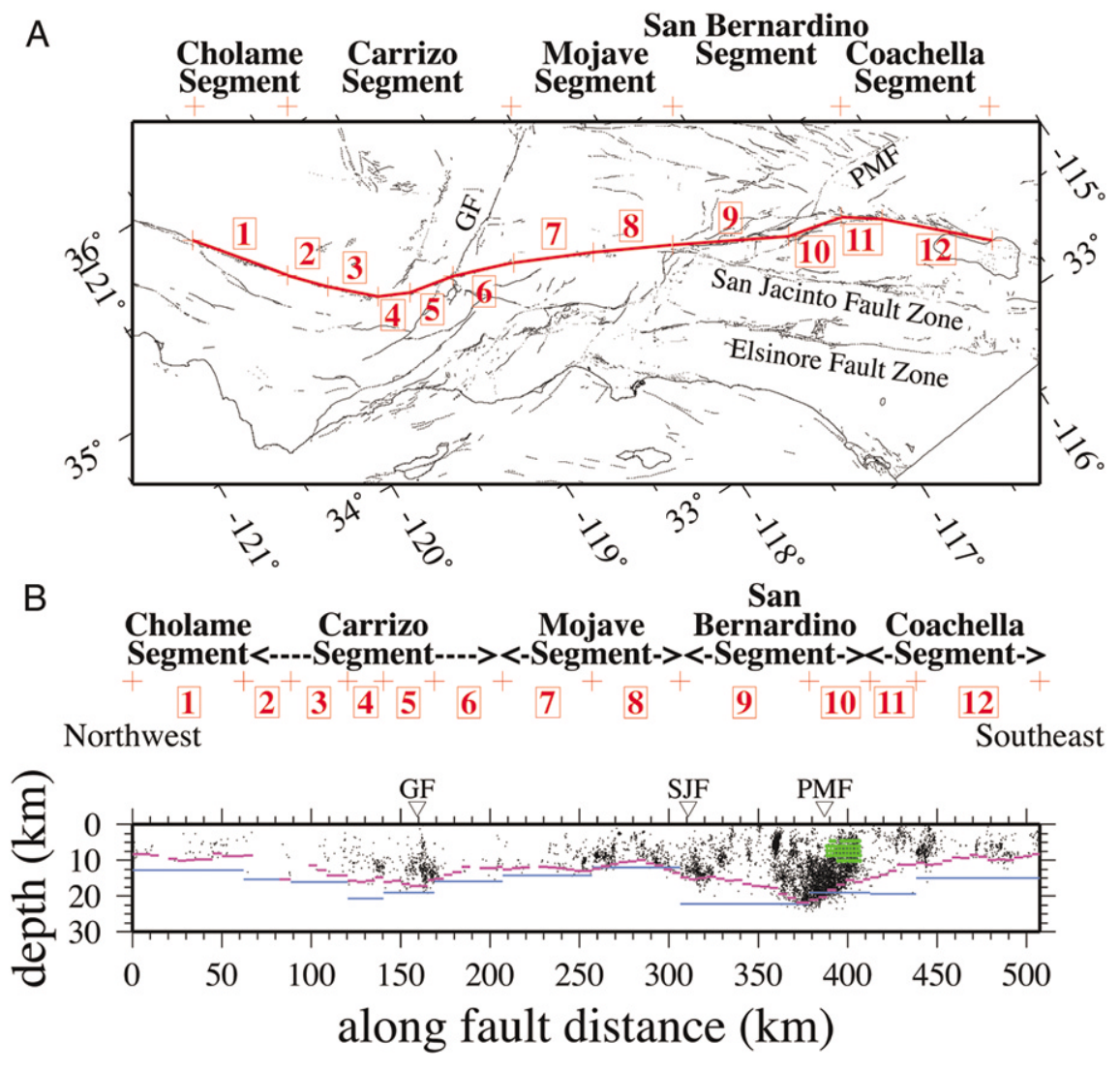

Figure 7. Central-Southern San Andreas fault zone. (A) Oblique map view showing the CDMG/USGS segments fault in red. Segments are divided into straight-line subsegments and numbered (in red) from north to south. GF, Garlock fault; PMF, Pinto Mountain fault. (B) Cross section along strike with projected earthquakes (black dots) and finite-source-model subfaults (parallel lines of green dots) within $5 \mathrm{~km}$ of the fault, smoothed seismogenic thickness estimates for 5-km along-strike bins (magenta lines), and seismogenic thickness estimates for whole subsegments (blue lines). Intersection and/or projection of faults with the San Andreas fault shown by inverted triangles: GF, Garlock fault; SJF, San Jacinto fault system; PMF, Pinto Mountain fault. Vertical exaggeration, $\times 2$. 
tends to $23 \mathrm{~km}$ depth and contains $91 \%$ of the moment release (excluding the 1986 M 6.1 North Palm Springs earthquake) of the San Andreas projected seismicity, but only $21 \%$ of the fault length. The northern left bend near Tejon Pass (subsegments 4 and 5) shows increased rate and maximum depth extent of seismicity compared with the surrounding fault segments, but contains significantly less moment release and a shallower maximum depth of seismicity than the southern end.

Seismogenic thickness estimates can differ by as much as $7 \mathrm{~km}$ within a CDMG/USGS fault segment. For instance, along the San Bernardino segment (subsegments 9 and 10), where the thickness estimate increases from 15 to $22 \mathrm{~km}$ and then decreases back to $15 \mathrm{~km}$, all over a length of $106 \mathrm{~km}$. Such a large variation along strike is somewhat unusual for a high-seismicity rate fault segment. Most of the other segments or subsegments with large variations in seismogenic thickness along-strike have sections with sparse seismicity, which reduces the reliability of the estimate.

San Jacinto Fault Zone. The San Jacinto fault zone is more complex than the San Andreas fault zone, with overlapping subparallel and parallel segments, and steps between the southern segments (Rockwell et al., 1990) (Fig. 8). The entire fault zone has a high seismicity rate and has ruptured in several major earthquakes during the past 2000 years (Gurrola and Rockwell, 1996). Two areas of significant, off-themain-trace, fault-parallel seismicity (Hot Springs and Buck Ridge faults) are not included in the CDMG/USGS fault database. Some seismicity, perhaps better attributed to these faults, lies within the 5-km limit of the CDMG/USGS trace, but most is excluded. The CDMG/USGS-defined fault segments are not always well aligned with either the mapped surface trace or seismicity alignments. This is especially true for the San Bernardino segment (subsegments 13 and 14), where both the mapped fault and the seismicity follow a curved path to the northeast. As a result, the "San Jacinto fault seismicity" has strike-perpendicular distances of 3-7 $\mathrm{km}$ from the defined straight line segment. A comparison of seismogenic thickness for seismicity $\pm 5 \mathrm{~km}$ versus $0-10$ $\mathrm{km}$ (the northeast side) from the defined segment yields nearly identical results, so we continue to use $\pm 5 \mathrm{~km}$ for this segment.

The projected seismicity and seismogenic thickness estimates for the San Jacinto fault zone are shown in Figure 8. The maximum depth of seismicity shallows relatively smoothly from $19 \mathrm{~km}$ at the northern end of the Anza segment (no. 17) south to $10-11 \mathrm{~km}$ at the parallel Superstition Mountain (no. 21) and Superstition Hills (no. 22) segments. The northernmost $10 \mathrm{~km}$ of the Imperial fault (no. 23) continues the trend, but further south, the maximum hypocenter depth deepens. The shallowing trend correlates with an increase of heat flow to the south as the fault approaches the Salton Trough (Doser and Kanamori, 1986; Sanders, 1987).

The seismogenic thickness of the San Jacinto fault zone varies significantly along strike (Fig. 8). The largest variation occurs along the Imperial fault (no. 23), where the large seismogenic thickness at the southernmost end is controlled by a $M 2.56$ earthquake at $23.3 \mathrm{~km}$ depth, which contains $0.9 \%$ of the moment release of the along strike bin. Although we present results for locations south of the international border, the seismogenic predictions should be used extremely cautiously because the hypocenter data are considered unreliable. The second largest variation occurs along the Coyote Creek segment (no. 19) where the seismogenic thickness decreases $6 \mathrm{~km}$ over a 41-km segment length, resulting in an approximate dip of $8^{\circ}$ in the seismogenic thickness. Subsegments to the north and south of Coyote Creek (no. 19) have dips in the seismogenic thickness of $2-3^{\circ}$. The subparallel Anza-2 (no. 18) subsegment shows a similar increase in dip relative to the surrounding segments, although the dip of $5^{\circ}$ is smaller than that for the Coyote Creek (no. 19) segment. This decrease in seismogenic thickness corresponds with a relative increase in heat flow to the southeast. A 4-km step in the maximum depth of hypocenters results in moderate variation in seismogenic thickness along the San Bernardino-1 (no. 13) subsegment. This step in hypocenters along the northern San Jacinto fault was noted by Magistrale and Sanders (1996) and linked to a change in basement lithology (Magistrale and Zhou, 1996). The smoothing process has widened the step in seismogenic thickness, but it is easily located between the fourth and fifth along-strike bins in the raw seismogenic thickness estimate.

Elsinore Fault Zone. The Elsinore fault zone is the third major component of the Pacific-North American plate boundary south of the Transverse Ranges in southern California (Vaughan et al., 1999). It and other less active faults to the west carry $10-15 \%$ of the plate boundary slip in southern California [Working Group on California Earthquake Probabilities (WGCEP), 1995]. The Elsinore fault zone has some subparallel fault segments and splits at the northern end into the Whittier fault (no. 24), and the Chino-Central Avenue fault (no. 31) in the Chino-Puente Hills. Near-fault seismicity occurs predominantly to the northeast side of the fault zone, except for the Whittier segment (no. 24) at the north end.

Seismogenic thickness varies from 10 to $21 \mathrm{~km}$ for the entire fault zone (Fig. 9). The deepest well constrained seismicity occurs along the northern half of the Julian segment (no. 27), where the Elsinore fault is double stranded (Magistrale and Rockwell, 1996). Seismogenic thickness decreases rapidly along the southern half of the Julian segment (no. 27), as the percent depth shallows $7 \mathrm{~km}$ over a length of $35 \mathrm{~km}$. This decrease suggests an apparent dip in the bottom of the seismogenic layer of $11^{\circ}$ along this section of the Elsinore fault. Percent depth levels rapidly along the Julian-Coyote Mountain segment boundary (subsegments $27 / 28$ ) to a dip of less than $2^{\circ}$. The thinning of the seismogenic crust continues along the northern $20 \mathrm{~km}$ of the La- 

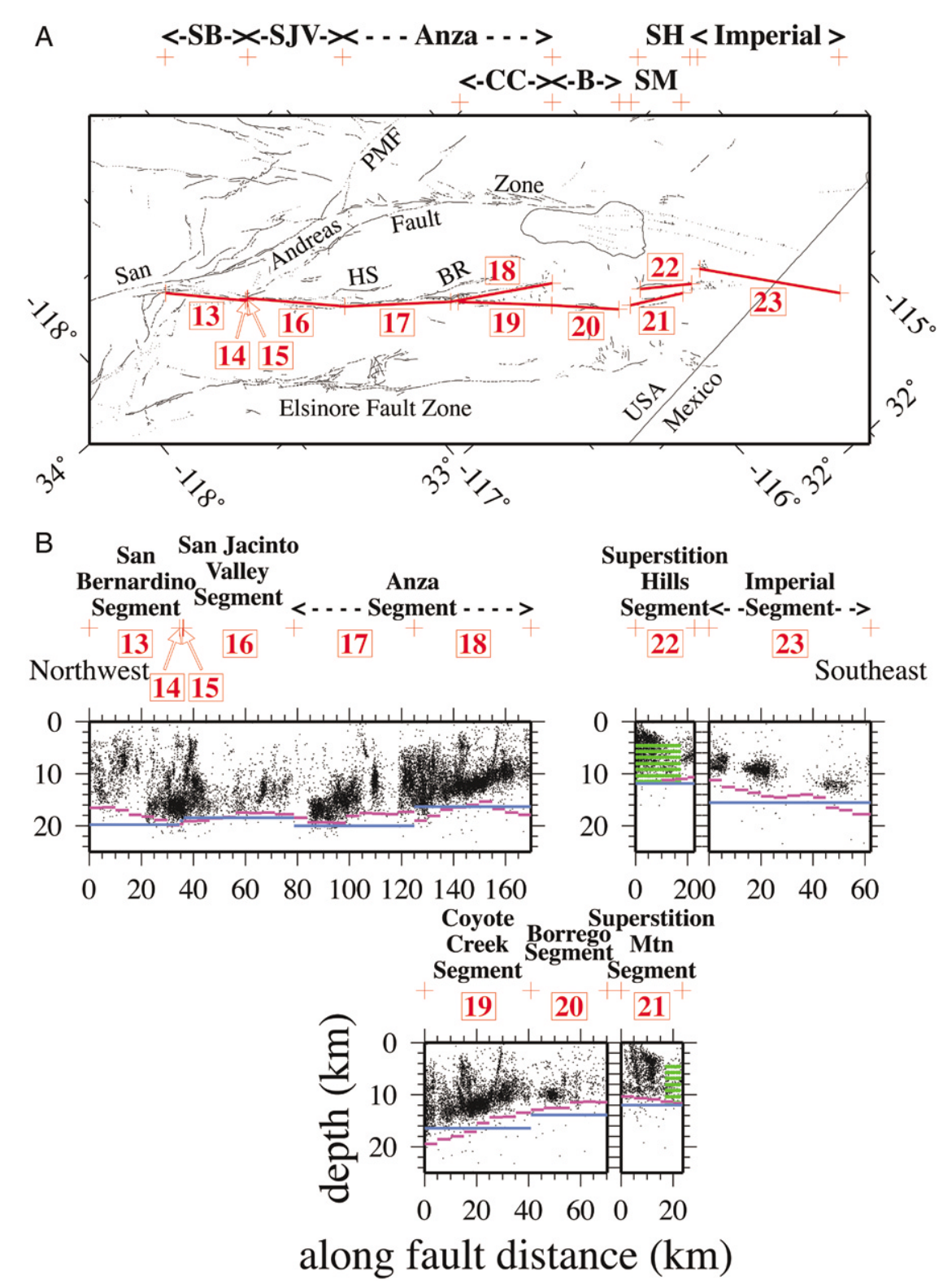

Figure 8. San Jacinto fault zone. (A) CDMG/USGS segments in red. SB, San Bernardino; SJV, San Jacinto Valley; CC, Coyote Creek; B, Borrego; SM, Superstition Mountain; SH, Superstition Hills; PMF, Pinto Mountain fault; HS, Hot Springs fault; BR, Buck Ridge fault. (B) Cross section along strike with projected earthquakes (black dots) and finite-source-model subfaults (parallel lines of green dots) within $5 \mathrm{~km}$ of the fault, smoothed seismogenic thickness estimates for 5-km along-strike bins (magenta lines), and seismogenic thickness estimates for whole subsegments (blue lines). Vertical exaggeration, $\times 2$.

guna Salada segment (nos. 29 and 30). This decrease in seismogenic thickness corresponds with a relative increase in heat flow to the southeast. Seismicity along the rest of the Laguna Salada segment (nos. 29 and 30) is extremely sparse, and the few hypocenters are considered poorly constrained because of their location a substantial distance south of the international border. As a result, the percent depths are erratic and the seismogenic thickness predictions for the Laguna Salada-2 subsegment no. 30 are poorly constrained.

\section{Discussion}

The Seismogenic Thickness of Tectonically Defined Regions

In this study, we provided a detailed view of seismogenic thickness at a resolution $\left(0.1^{\circ} \times 0.1^{\circ}\right.$ bins $)$, deemed the most appropriate for the earthquake population of most parts of southern California. To compare the seismogenic thickness with geological and tectonic features, we use the 


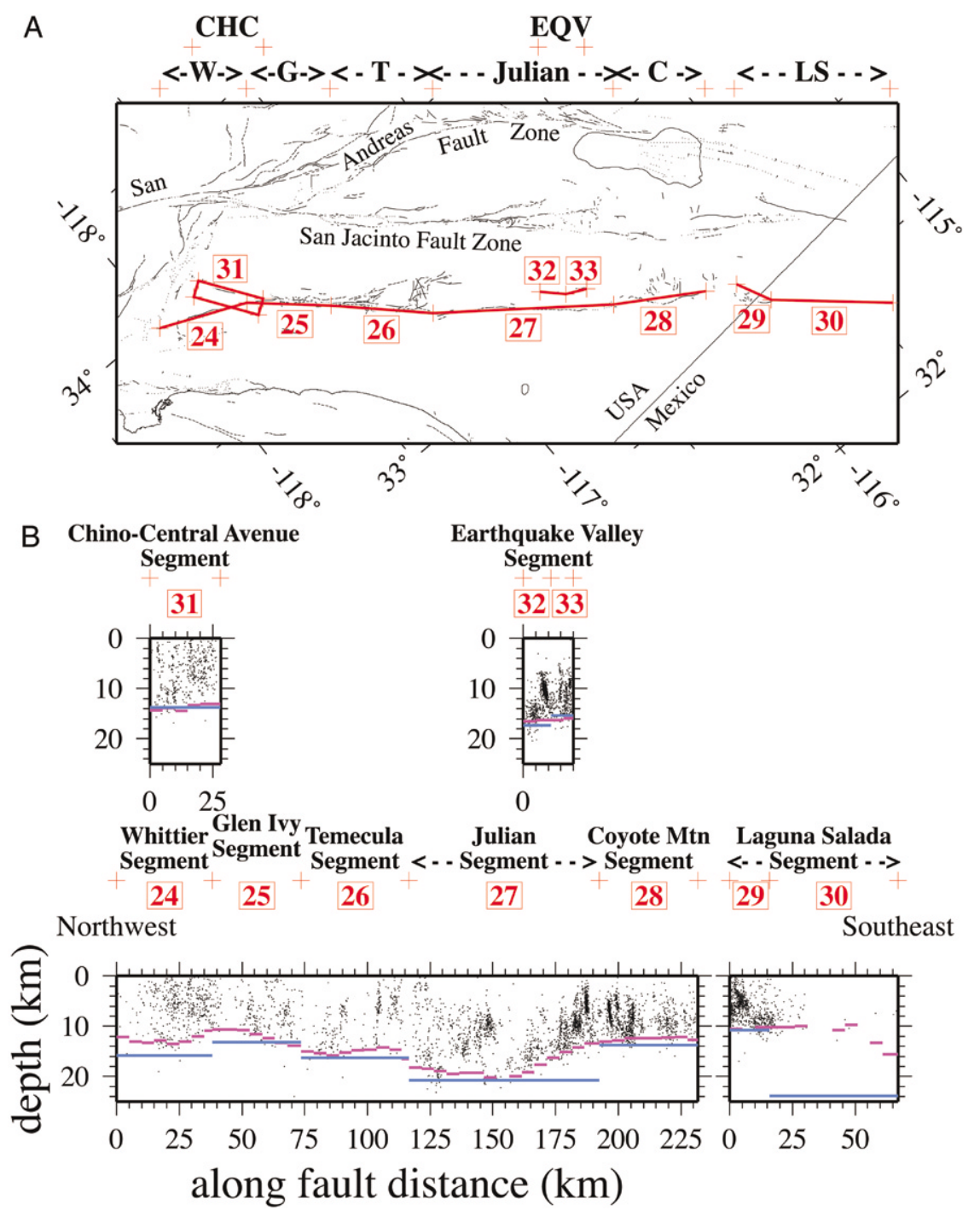

Figure 9. Elsinore fault zone. (A) CDMG/USGS segments in red. Segment names: W, Whittier; G, Glen Ivy; T, Temecula; C, Coyote Mountain; LS, Laguna Salada; CHC, Chino-Central Avenue; EQV, Earthquake Valley. (B) Cross section along strike with projected earthquakes (black dots) located within $5 \mathrm{~km}$ of the fault, smoothed seismogenic thickness estimates for 5-km along-strike bins (magenta lines), and seismogenic thickness estimates for whole subsegments (blue lines). Vertical exaggeration, $\times 2$.

65 source zones of the SCEC Phase II report (WGCEP, 1995) to test whether dividing southern California into polygons based on geological information is a reasonable alternative to the high-resolution regional bins. Of these zones (types A and B) 41 are narrow polygons (usually $\sim 15-20 \mathrm{~km}$ wide) centered on the major faults. The remaining 24 zones (type C) cover the rest of southern California in-between and adjacent to the zones containing faults. These zones were inferred from surface geology, paleoseismic data, and geodetic data to characterize typical earthquake rupture extent.

We compared the seismogenic thickness estimate calculated from all seismicity located within each source zone with the average of the seismogenic thickness predictions of the regional bins located inside each source zone. A regional bin is considered to be inside if the center of the regional bin is located inside the source-zone polygon. The average seismogenic thickness is based on regional bins with ten or more earthquakes.

For most of the Southern California Earthquake Center (SCEC) source zones, the seismogenic thickness is not appropriately described by a single value such as the mean seismogenic thickness (Table 2). Seismogenic thickness often varies significantly within a source zone. The variation of seismogenic thickness within a source zone (as measured by both the standard deviation of the mean and the difference between the minimum and maximum values) is approximately proportional to the area of the polygon. This is not too surprising, because the larger the region, the more 
Table 2

Seismogenic Thickness of Tectonically Defined Regions

\begin{tabular}{|c|c|c|c|c|c|c|c|c|c|}
\hline $\begin{array}{l}\text { Source } \\
\text { Zone }\end{array}$ & $\begin{array}{l}\text { All Seis. } \\
\text { ST (km) }\end{array}$ & $\begin{array}{l}\text { Ave. RB } \\
\text { ST (km) }\end{array}$ & $\begin{array}{c}\text { Num. } \\
\text { RB }\end{array}$ & $\begin{array}{l}\text { Source Zone } \\
\text { Description }\end{array}$ & $\begin{array}{l}\text { Source } \\
\text { Zone }\end{array}$ & $\begin{array}{l}\text { All Seis. } \\
\text { ST (km) }\end{array}$ & $\begin{array}{l}\text { Ave. RB } \\
\text { ST (km) }\end{array}$ & $\begin{array}{l}\text { Num. } \\
\text { RB }\end{array}$ & $\begin{array}{l}\text { Source Zone } \\
\text { Description }\end{array}$ \\
\hline \multicolumn{10}{|l|}{ Type A } \\
\hline 4 & 20.8 & 17.0 & 13 & SAF-Carrizo Segment & 34 & 14.0 & 14.0 & 15 & Palos Verdes Fault \\
\hline 5 & 14.6 & 12.9 & 18 & SAF-Mojave Segment & 35 & 17.8 & 14.7 & 4 & Santa Cruz Island \\
\hline 6 & 19.9 & 18.2 & 16 & SAF-San Bernadino Mtns Segment & 37 & 10.1 & & 0 & Rinconada Fault \\
\hline 7 & 15.7 & 13.9 & 20 & SAF-Coachella Segment & 38 & 14.4 & & 0 & Hosgri Fault-north \\
\hline 8 & 19.8 & 19.6 & 4 & SJF-San Bernadino Valley Segment & 39 & 11.0 & & 0 & Hosgri Fault—south \\
\hline 9 & 18.6 & 18.8 & 8 & SJF-San Jacinto Valley Segment & 40 & 21.2 & 15.5 & 23 & Santa Ynez Fault System \\
\hline 10 & 19.9 & 18.7 & 15 & SJF-Anza Segment & 41 & 18.3 & 12.9 & 13 & Sierra Nevada Frontal Fault System \\
\hline 11 & 15.2 & 15.4 & 4 & SJF-Coyote Creek Segment & 54 & 20.4 & 18.6 & 11 & Simi Hills-San Fernando Valley \\
\hline 12 & 13.9 & 11.5 & 6 & SJF-Borrego Segment & Type C & & & & \\
\hline 13 & 13.0 & 13.1 & 6 & SJF Superstition Mtns Segment & 36 & 12.1 & & 0 & Santa Rosa Island \\
\hline 14 & 12.0 & 12.0 & 3 & SJF Superstition Hills Segment & 42 & 14.5 & 14.2 & 16 & San Bernadino Mountains \\
\hline 15 & 16.0 & 15.8 & 13 & Whittier Fault & 43 & 16.3 & 13.7 & 4 & West Mojave \\
\hline 16 & 16.4 & 14.2 & 7 & ELF-Glen Ivy Segment & 44 & 17.2 & 12.5 & 89 & Central Mojave \\
\hline 17 & 17.2 & 14.6 & 5 & ELF-Temecula Segment & 45 & 10.0 & 14.4 & 9 & Salton Trough \\
\hline 18 & 20.4 & 17.5 & 14 & ELF-Julian Segment & 46 & 22.8 & 17.9 & 15 & Ventura Basin \\
\hline 19 & 13.3 & 13.2 & 8 & ELF-Coyote Mtns Segment & 47 & 18.8 & 13.7 & 13 & Northeast Mojave \\
\hline Type B & & & & & 48 & 11.7 & 12.0 & 17 & Coso Region \\
\hline 1 & 15.0 & 11.9 & 4 & SAF_-Creeping Section & 49 & 21.4 & 13.3 & 3 & San Gabriel Mountains \\
\hline 2 & 15.6 & 11.7 & 4 & SAF_-Parkfield Segment & 50 & 11.9 & & 0 & Central Coast Ranges \\
\hline 3 & 12.9 & 8.8 & 2 & SAF-Cholame Segment & 51 & 15.6 & & 0 & Central Coast \\
\hline 20 & 18.0 & 15.2 & 13 & Newport-Inglewood Fault & 52 & 23.3 & 21.8 & 13 & West San Joaquin Valley \\
\hline 21 & 14.9 & 14.0 & 2 & Newport-Inglewood Fault Offshore & 53 & 28.1 & 19.4 & 9 & Central San Joaquin Valley \\
\hline 22 & 14.9 & 13.9 & 1 & Rose Cyn Fault & 55 & 20.2 & 14.1 & 6 & Santa Barbara Channel \\
\hline 23 & 16.9 & 15.7 & 11 & Imperial Fault & 56 & 25.2 & 16.3 & 31 & Offshore Islands \\
\hline 24 & 16.4 & 13.3 & 11 & Laguna Salada Fault & 57 & 16.2 & & 0 & Central Offshore \\
\hline 25 & 25.1 & 17.6 & 24 & White Wolf Fault & 58 & 20.6 & 14.6 & 18 & Western Peninsular Ranges \\
\hline 26 & 15.2 & 20.7 & 1 & Big Pine Fault & 59 & 17.4 & 15.6 & 32 & Central Peninsular Ranges \\
\hline 27 & 14.9 & 12.0 & 14 & Garlock Fault—west & 60 & 17.3 & 14.6 & 50 & Southern Sierra Nevada \\
\hline 28 & 19.0 & 12.0 & 13 & Garlock Fault—east & 61 & 14.8 & 10.7 & 16 & Southern Basin-Ranges \\
\hline 29 & 12.5 & 13.2 & 11 & Pinto Mountain Fault & 62 & 14.2 & & 0 & Eastern Mojave \\
\hline 30 & 10.0 & 10.2 & 8 & Brawley Seismic Zone & 63 & 20.2 & 13.3 & 2 & Colorado Corridor \\
\hline 31 & 16.4 & 14.7 & 15 & Sierra Madre Fault & 64 & 15.0 & 13.5 & 20 & Southeast Corner \\
\hline 32 & 18.5 & 17.2 & 10 & San Gabriel Fault & 65 & 11.5 & 10.1 & 3 & Western Transverse Ranges \\
\hline 33 & 17.5 & 17.2 & 11 & Santa Monica-Malibu Fault System & & & & & \\
\hline
\end{tabular}

Source Zone, polygon based on geological information and separated into tree types, as defined in the SCEC Phase II report (WGCEP, 1995); All Seis. ST, seismogenic thickness estimate calculated from the moment release of all seismicity located within the source zone; Ave. RB ST, average seismogenic thickness prediction of the regional bins located within each source zone; Num. RB, number of regional bins located within the source zone; SAF, San Andreas fault; SJF, San Jacinto fault; ELF, Elsinore fault.

chance there is to encounter differences in the physical parameters that control the seismogenic thickness.

Another consideration is how the polygon is drawn. One bin or a small region can dominate the whole polygon seismogenic thickness estimate or skew the average (Fig. 10). This is a special concern for polygons containing a limited number of earthquakes. The normal tendency is to cover a region with sparse earthquakes with a large polygon, because we have no basis to make detailed estimates for most of the area. The seismogenic thickness estimate for the limited area of the polygon with earthquakes will be extended to represent the whole region covered by the polygon. If the polygon boundary is not correct or lacks sufficient detail, or the limited area with earthquakes has an anomalous seismogenic thickness, then the incorrect or anomalous seismogenic thickness will be extended inappropriately across the entire region defined by the polygon. In these cases, it is not always clear whether more detail is warranted in the definition of the polygon, or whether the seismogenic thickness does not correspond to boundaries seen in surface data.

In general, polygons based on geological information (as commonly defined) are not a reasonable alternative to high-resolution bins. The seismogenic thickness of the southern California crust tends to vary on scales smaller than the geologic or tectonic provinces commonly defined. A detailed estimate of seismogenic thickness, such as that provided by smoothed regional $0.1^{\circ} \times 0.1^{\circ}$ bins (Fig. 6), should be used wherever possible. The filtering process averages on a small scale so local variations are maintained, yet it smoothes the regions with sparse seismicity and fills in central empty regional bins through interpolation. 


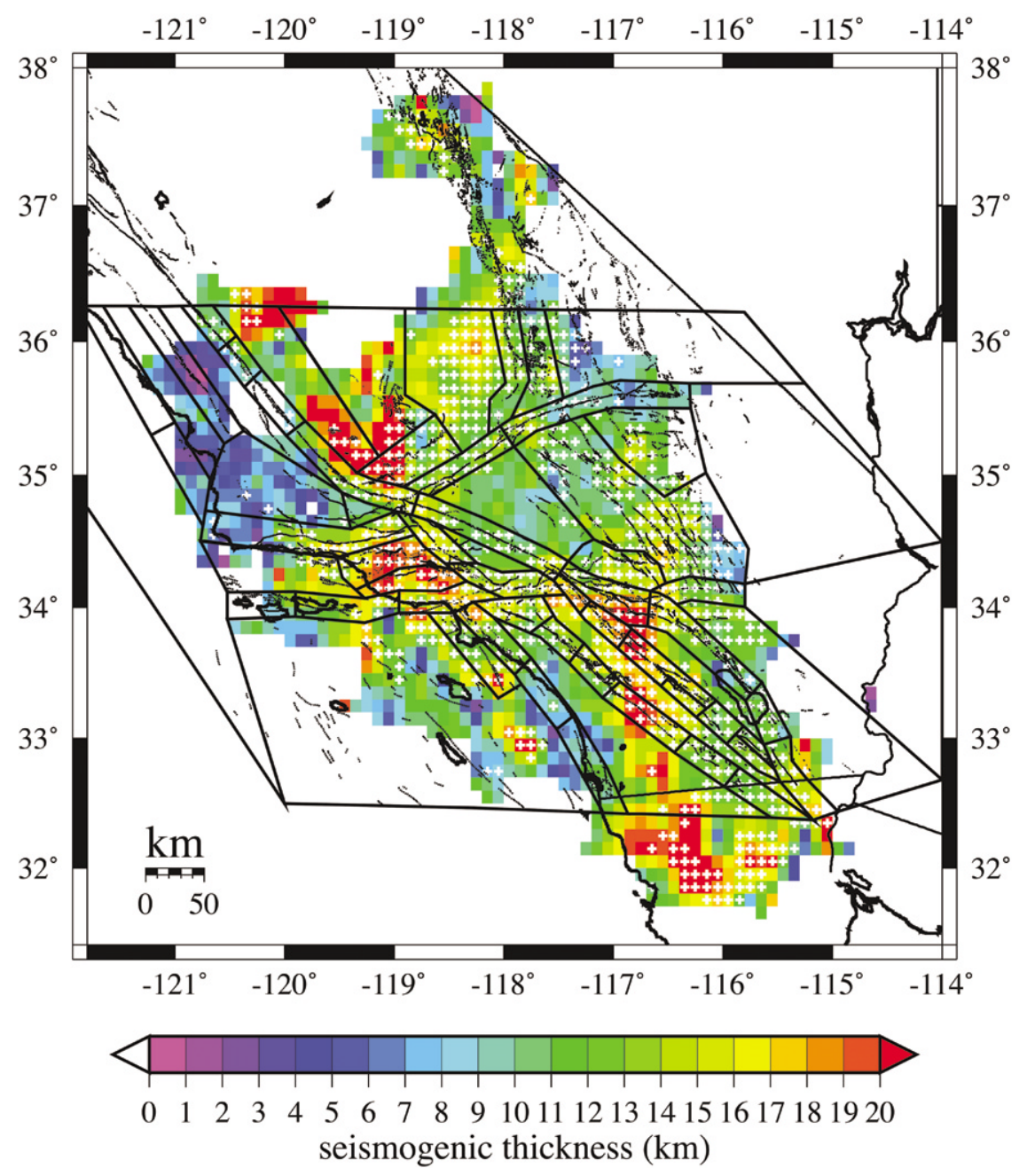

Figure 10. SCEC source-zone boundaries imposed on the smoothed seismogenic thickness for all regional bins. The regional bins are smoothed as in Figure 4, and the white crosses mark regional bins considered to have reliable seismogenic thickness estimates. Note the local variation in seismogenic thickness within most source-zone boundaries.

Implications for the CDMG, USGS, and SCEC Fault Database

As part of seismic hazards analysis, a model of the seismic sources is created that describes the magnitude, location, and rate of earthquakes that pose a significant hazard to the region in question. In turn, this source model is used to calculate the probability of future damaging earthquakes and/ or to calculate the probability of damaging ground motions. The detail and accuracy of the source model is important to the usefulness and applicability of the seismic hazard assessment.

One example of such a source model is the CDMG/USGS fault database for California (Peterson et al., 1996). It improved on the fault database of the SCEC Phase II report (WGCEP, 1995) by adding the down-dip width, rupture top, and rupture bottom of the fault segments. This study improves on the CDMG/USGS database by quantitatively esti- mating the seismogenic thickness (equivalent to the downdip width for vertical faults that break the surface) systematically and in detail for the San Andreas, San Jacinto, and Elsinore fault zones.

We provide the modifications to the southern California source model in terms of the variable seismogenic thickness, $H$, and compare it with the CDMG/USGS rupture bottom, $R B$ (equivalent to our seismogenic thickness for these segments because the rupture top is at the surface) in Table 1. We list the whole subsegment (WSS) estimate and the subsegment smoothed 5-km along-strike bins mean, minimum, and maximum, to show the variation of the seismogenic thickness within the subsegment. The whole subsegment seismogenic thickness, as tabulated in the CDMG/USGS fault database, tends toward the maximum of the segment, so it often overestimates the seismogenic thickness for much of the subsegment when there is large variation along strike. The 
maximum seismogenic thickness of the smoothed $5-\mathrm{km}$ along-strike bins is usually less than the whole subsegment estimate because the smoothing process reduces the maximum value by averaging with the surrounding lesser values.

The mean of the smoothed 5-km along-strike bins seismogenic thickness for each subsegment is usually within $3 \mathrm{~km}$ of the CDMG/USGS estimate. Often, the difference is $2 \mathrm{~km}$ or less, which is within the stated error for the CDMG/ USGS database. If the average thickness of the segment was the same as the database, then the rupture plane would have the same area, and for constant slip along strike during rupture, then total moment release would be the same. Far enough away from the fault segment, the difference in faultplane definition (5-km along-strike variable depth rectangles versus a single rectangle with identical area) would not matter. Locally, however, the variable size rupture plane along strike could produce noticeable differences in seismic moment release.

The largest uncertainty in rupture size derived from the CDMG/USGS database is not that the whole-segment rupture bottom estimates are biased (which they are at times), but that the parameters in the database do not describe the significant variation in seismogenic thickness within a segment or even a subsegment. In most cases, using one value (e.g., an average or a maximum) for the seismogenic thickness of a segment or subsegment is inappropriate. The longer the segment length, the more this seems to be true. A key point here is that segmentation of the major strike-slip faults of southern California (based on surface features) does not necessarily correspond to the variations in seismogenic thickness (potential down-dip width) along strike of the fault. Such refinements should be included in future improvements to the seismic hazards models. Alternatively, the idea of segmentation may be replaced with a continuous distribution of events that could rupture in a random fashion across these geometrical complexities.

\section{Seismic Hazard Implications}

A model of seismic sources describes the magnitude, location, and rate of earthquakes that pose a significant hazard to the region in question. Seismic hazard assessments use such models to measure the seismic potential of a fault or a region. Such source models are usually constrained by the overall seismic moment rate, so that the source model reflects the tectonic loading of the region. The moment rate of the region can be estimated from geological or fault data, geodetic data (strain rate), the relative tectonic motion between plates, and the historical earthquake catalog (Field et al., 1999). The first three methods depend linearly on the assumed seismogenic thickness and, thus, can be improved with better estimates of seismogenic thickness (Field et al., 1999). The fourth method depends on the accuracy and completeness of the historical catalog, making this method applicable to a different timescale (Field et al., 1999).

A key component of many seismic hazard source models is the maximum or characteristic magnitude of a fault or region. As the largest earthquakes dominate the seismic moment release budget of a region, the determination of this value is critical (Field et al., 1999). The maximum possible magnitude is often based on the length of the fault (e.g., WGCEP, 1995), or the area of the fault (e.g., WGCEP, 1995; Peterson et al., 1996; Field et al., 1999), with constraints on the down-dip width [i.e., seismogenic thickness (WGCEP, 1995)] or recurrence interval of the fault from the seismic moment rate (e.g., WGCEP, 1995; Field et al., 1999). To show the effect of seismogenic thickness on this magnitude, we calculate the difference in magnitude, $m$, by combining the equations for seismic moment and moment magnitude [equations 1 and 2 from the SCEC report (WGCEP, 1995)].

$$
\Delta m=\left(\frac{2}{3}\right) \log \left(\frac{H_{2}}{H_{1}}\right) .
$$

The SCEC Phase II report (WGCEP, 1995) assumed a seismogenic thickness of $11 \mathrm{~km}$ for all of southern California, but we calculate the average seismogenic thickness from our regional analysis to be $15.0 \mathrm{~km}$. The difference in magnitude due to an increase of $4 \mathrm{~km}$ in seismogenic thickness (from $H_{1}=11 \mathrm{~km}$ to $H_{2}=15 \mathrm{~km}$ ) is 0.09 . Although this seems small, it is on the same order as the rounding of magnitudes that was cited as one of the reasons why the SCEC Phase II report overestimated the rate of magnitude 6 and 7 earthquakes, relative to the historic rate (Field et al., 1999).

Multiple parameters of most seismic hazard assessments depend on the assumed value of the seismogenic thickness of the crust. These parameters are often interdependent. The seismic potential of a source model may be dominated by the maximum-magnitude earthquakes (estimated from the area and, therefore, seismogenic thickness of the contributing faults), yet this potential is constrained by the seismic moment release of the region (which linearly depends on the same seismogenic thickness). The reliability of such seismic hazard assessments depends on the accuracy of the thickness of the seismogenic crust of the region. Future improvements in seismic hazard assessments depend on improvements in the accuracy and detail of vital parameters such as seismogenic thickness.

\section{Conclusions}

Regional premainshock seismicity can predict the maximum depth of rupture for moderate to large earthquakes in southern California. We have quantitatively established that the depth down to which $99.9 \%$ of the moment release of earthquakes occurs reliably estimates the maximum depth of rupture during moderate to large earthquakes. Unlike previous studies, we use the moment release depth distribution of seismicity rather than simply the hypocenter distribution, because moment release produces more precise estimates with smaller errors that mitigate uncertainties in focal depths and effects from scattered hypocentral depth distributions. 
Further, the good agreement between the moment release of small and large earthquakes suggests that both exhibit selfsimilar behavior. We assume that the maximum depth of rupture during these larger events is synonymous with seismogenic thickness and, therefore, we can estimate the seismogenic thickness in a systematic and widespread fashion for southern California.

We predict the seismogenic thickness for a regional viewpoint using $0.1^{\circ} \times 0.1^{\circ}$ bins. The seismogenic thickness of southern California is highly variable, ranging from less than $10 \mathrm{~km}$ in the Salton Trough to greater than $25 \mathrm{~km}$ at the southwestern edge of the San Joaquin Valley. The average seismogenic thickness for southern California is 15.0 $\mathrm{km}(+1.2 /-1.1 \mathrm{~km})$. The seismogenic thickness varies significantly within individual fault segments for the three major strike-slip zones in southern California. Surface segmentation of these faults does not reflect the variations in seismogenic thickness and their potential down-dip width. Faults could be divided into smaller segments/subsegments than have been used in the past. Regardless of the length of fault that is expected to rupture in a single earthquake, the fault segments/subsegments should be redesigned to take into account the rapid variations in seismogenic thickness along strike.

\section{Appendix}

We infer the seismogenic thickness from the threedimensional distribution of seismic moment release. We use the moment release of background seismicity and the moment release of mainshocks that have been modeled as finite sources.

\section{Distributing Seismic Moment into Depth Bins}

To calculate the distribution of seismic moment release with depth, we divide each depth column into bins. We center the fault plane at the earthquake hypocenter and distribute the moment into the depth bins that the fault plane overlaps. We estimate the moment release from the magnitude moment relationship of Hanks and Kanamori (1979),

$$
M o=10^{\left(\left(1.5 \times M_{1}\right)+9.05\right)}
$$

where $M o$ is the seismic moment and $M_{1}$ is the local magnitude (we use moment magnitude for $M \geq 6$ ). The downdip width of the fault plane is estimated from the magnitude

$$
w=\sqrt{10^{\left(\left(M_{1}-4.07\right) / 0.98\right)}}
$$

(from Wells and Coppersmith, 1994) where $w$ is width (assuming a square rupture plane), and $M_{1}$ is local magnitude. If the plane overlaps more than one depth bin, the moment is divided among the depth bins according to the proportion of overlap between the fault plane and the respective depth bin. When the plane intersects the surface, we put the top of the rupture plane at the surface and distribute the moment downward from there.

For large earthquakes $(M>5)$, we use the seismic moment release distribution provided by available finite-source slip models. We have assembled 19 finite-source models for 12 moderate- to large-magnitude southern California earthquakes (Table A1). We consider multiple finite-source models for several earthquakes when we calibrate regional seismicity as a predictor of maximum rupture during larger earthquakes. In our determination of 3D seismic moment release, however, we use the slip model that we consider to be best, based on the dataset(s) used to create the finitesource model.

Two potential errors can affect the moment release depth distribution technique described previously: (1) the potential mislocation in the depth of the hypocenter (vertical error) and (2) the uncertainty in the distribution of the moment release about the hypocenter (which means that we do not know where the rupture progressed after initiation at the hypocenter). We have assumed in the previously presented technique that half of the rupture occurred above and half below the hypocenter. These errors have little effect on the depth distribution of moment within a region, except if an earthquake contains a significant proportion of the moment release of the region and occurs relatively deep within the depth column.

For small-magnitude earthquakes, the vertical error often exceeds the width of the rupture plane. For instance, a $M_{\mathrm{L}} 3.5$ earthquake has an estimated rupture width of approximately $0.5 \mathrm{~km}$, which is equal to the vertical error for $55 \%$ of the earthquakes in our database. For small earthquakes (which constitute most of our dataset), it is reasonable to assume that the hypocenter is the center of a small patch of slip. This means that the dominant error for small earthquakes is the vertical error.

For moderate- and large-magnitude earthquakes, the dominant error tends to be the uncertainty in the distribution of moment release away from the hypocenter. Although it has been suggested that most large earthquakes initiate near the base of the seismogenic crust and rupture mostly up-dip of the hypocenter (Sibson, 1982), a sufficient number of larger earthquakes have initiated at shallow depths to disallow that simple assumption (e.g., 1987 Superstition Hills earthquake, 1992 Landers earthquake, and 1999 Hector Mines earthquake). In fact, the largest error in estimating the depth distribution of moment release from large earthquakes is that the slip is variable, and it is no longer appropriate to assume a square rupture plane and constant slip on the plane. As a result, we use published finite-source models wherever possible for the moderate to large earthquakes in our dataset. Moderate to large earthquakes without finite-source models are treated like small earthquakes (with even depth distribution of moment release).

Finite-Source Models

In Table A2 we list the overall rupture dimensions of the slip models. Some models consist of more than one 
Table A1

Finite-Source Models

\begin{tabular}{|c|c|c|c|c|c|c|}
\hline Earthquake & Model & $\begin{array}{c}\text { Date } \\
(\mathrm{mm} / \mathrm{dd} / \mathrm{yy})\end{array}$ & Mech. & Mo (N m) & $M_{\mathrm{W}}$ & Reference \\
\hline North Palm Springs & NPS & $07 / 08 / 86$ & OB & $1.77 \mathrm{E}+18$ & 6.13 & Hartzell, 1989 \\
\hline Whittier Narrows & WN & $10 / 01 / 87$ & TH & $9.45 \mathrm{E}+17$ & 5.95 & Hartzell and Iida, 1990 \\
\hline Elmore Ranch & ER & $11 / 24 / 87$ & SS & $2.31 \mathrm{E}+18$ & 6.21 & Larsen et al., 1992 \\
\hline \multirow[t]{2}{*}{ Superstition Hills } & SH-W & $11 / 24 / 87$ & SS & $4.81 \mathrm{E}+18$ & 6.42 & Wald et al., 1990 \\
\hline & SH-L & & & $9.76 \mathrm{E}+18$ & 6.63 & Larsen et al., 1992 \\
\hline Upland & UP & $02 / 28 / 90$ & TH & $2.51 \mathrm{E}+17$ & 5.57 & Dreger and Helmberger, 1991 \\
\hline Sierra Madre & $\mathrm{SM}$ & $06 / 28 / 91$ & $\mathrm{TH}$ & $2.84 \mathrm{E}+17$ & 5.60 & Wald, 1992 \\
\hline \multirow[t]{2}{*}{ Joshua Tree } & JT-B & $04 / 23 / 92$ & SS & $1.69 \mathrm{E}+18$ & 6.12 & Bennett et al., 1995 \\
\hline & JT-HD & & & $1.46 \mathrm{E}+18$ & 6.08 & Hough and Dreger, 1995 \\
\hline Landers & $\mathrm{L}$ & $06 / 28 / 92$ & SS & $7.74 \mathrm{E}+19$ & 7.23 & Wald and Heaton, 1994 \\
\hline Big Bear & $\mathrm{BB}$ & $06 / 28 / 92$ & SS & $5.53 \mathrm{E}+18$ & 6.46 & Jones and Hough, 1995 \\
\hline \multirow[t]{5}{*}{ Northridge } & $\mathrm{N}-\mathrm{W}$ & 01/17/94 & $\mathrm{TH}$ & $1.39 \mathrm{E}+19$ & 6.72 & Wald et al., 1996 \\
\hline & N-DR & & & $1.19 \mathrm{E}+19$ & 6.68 & Dreger, 1994 \\
\hline & $\mathrm{N}-\mathrm{HU}$ & & & $1.05 \mathrm{E}+19$ & 6.65 & Hudnut et al., 1996 \\
\hline & $\mathrm{N}-\mathrm{HV}$ & & & $1.63 \mathrm{E}+19$ & 6.77 & Hudnut et al., 1996 \\
\hline & $\mathrm{N}-\mathrm{S}$ & & & $1.52 \mathrm{E}+19$ & 6.75 & Shen et al., 1996 \\
\hline Northridge Aftershock & AN & $01 / 17 / 94$ & $\mathrm{TH}$ & $1.01 \mathrm{E}+18$ & 5.97 & Dreger, 1997 \\
\hline \multirow{2}{*}{ Hector Mines } & HM-J & $10 / 16 / 99$ & SS & $6.19 \mathrm{E}+19$ & 7.16 & Ji et al., 2002 \\
\hline & HM-K & & & $6.72 \mathrm{E}+19$ & 7.18 & Kaverina et al., 2000 \\
\hline
\end{tabular}

Under "Model" are the letter designations used in this study to reference the particular finite-rupture model. Mech, rupture mechanism; Mo, seismic moment; Mw, moment magnitude; OB, oblique; TH, thrust; SS, strike slip.

plane. In many slip models, the rupture plane or planes overestimate the "true" rupture area of the earthquake to ensure that all the slip can be accommodated on the plane during the inversion (Somerville et al., 1999; Mai and Beroza, 2000). This overestimation of the rupture area results in rows or columns on the edges of the model that have very little or even zero slip. We use the trimming criterion of Somerville et al. (1999) to trim rows and columns from our slip models. The criterion is simple; if the average slip per subfault of the row or column located on the edge of the model is less than 0.3 times the average slip of the whole fault, then the row or column is removed from the reference model. One edge row or column is removed at a time, starting with the lowest average slip first and continuing until all edge rows or columns have the requisite average slip.

The results of the trimming process are shown in Table A3. Thirteen of the models required trimming. The reduction in moment release of the models was $7 \%$ on average, which resulted in an average decrease in event magnitude of 0.02 units. The 16 models used for the comparison with background seismicity (the reference models) are NPS, WN, ER, SH-W, SH-L, SM, JT-B, JT-HD, L, N-W, N-DR, N-HU, N$\mathrm{HV}, \mathrm{N}-\mathrm{S}, \mathrm{HM}-\mathrm{J}$, and HM-K. Three of the slip models were not used in the analysis because of insufficient quality (UP and $\mathrm{BB}$ ) or because they represented an aftershock (AN). We did not use model BB because we had to estimate the depth extent of rupture plane and assumed constant slip. The main plane of model UP was sufficiently defined, but the location and orientation of the large asperity with $30 \%$ of the total moment was poorly defined. Even though the three models have large uncertainties associated with them, we use the three models in the prediction portion of our project, because the moment release is better defined by the finitesource models than it would be if we had to use empirical formulas. The 12 models used to represent the moment release of the earthquakes for the prediction phase are marked with an asterisk (*) in Table A3.

\section{Moment Release and Hypocenter Distribution Test Excluded Slip Models}

Four of the sixteen reference models were excluded from the calculation of the appropriate value of moment percent and hypocenter percent for the prediction of seismogenic thickness. Reference slip models WN and SM were excluded because the premainshock background seismicity was extremely sparse ( $\leq$ eight earthquakes), and the result was unreliable as a predictor of seismogenic thickness. The other two excluded models (NPS and N-HU) are discussed next.

The North Palm Springs (model NPS) earthquake occurred on the boundary between two regions with maximum earthquake depths that differ by $5 \mathrm{~km}$ (Magistrale and Sanders, 1996). The fault plane dips to the northeast and bottoms into the corner of the step in earthquake hypocenters. Most of the slip-model fault plane lies over the region of deeper seismicity, so the background seismicity has over $55 \%$ of moment release deeper than the bottom of the slip model. However, the slip-model rupture plane bottoms in the region of shallower seismicity, so the bottom of the rupture plane is consistent with the depth of the background seismicity of the region on the northeast side of the step in seismicity. If only background seismicity to the northeast of the slip- 
Table A2

Finite-Source Model (Untrimmed) Rupture Dimensions

\begin{tabular}{|c|c|c|c|c|c|c|c|c|c|}
\hline Slip Model & Columns & Rows & Length $(\mathrm{km})$ & Width $(\mathrm{km})$ & Top (km) & Bottom (km) & Dip $\left(^{\circ}\right)$ & Strike $\left(^{\circ}\right)$ & View $\left(^{\circ}\right)$ \\
\hline NPS & 11 & 8 & 22.00 & 15.20 & 4.00 & 14.93 & 46 & 287 & 17 \\
\hline WN & 10 & 10 & 10.00 & 10.00 & 12.00 & 17.00 & 30 & 280 & 10 \\
\hline ER & 10 & 5 & 25.00 & 10.00 & 0.00 & 10.00 & 90 & 40 & 310 \\
\hline SH-W & 20 & 10 & 20.00 & 11.50 & 0.50 & 12.00 & 90 & 127 & 217 \\
\hline SH-L & 10 & 5 & 25.00 & 10.00 & 0.00 & 10.00 & 90 & 310 & 40 \\
\hline UP: main & 2 & 2 & 3.50 & 3.50 & 6.00 & 9.36 & 74 & 215 & 305 \\
\hline UP: asp. & 1 & 1 & 1.00 & 1.00 & 8.00 & 9.00 & 90 & 215 & 305 \\
\hline SM & $\begin{array}{c}7 \\
(10)\end{array}$ & 10 & $\begin{array}{c}4.90 \\
(7.00)\end{array}$ & 6.00 & 9.40 & 14.00 & 50 & 242 & 332 \\
\hline JT-B & $\begin{array}{c}29 \\
(35)\end{array}$ & 20 & $\begin{array}{c}29.00 \\
(35.00)\end{array}$ & 20.00 & 0.00 & 20.00 & 90 & 172 & 262 \\
\hline JT-HD & $\begin{array}{c}25 \\
(30)\end{array}$ & $\begin{array}{c}13 \\
(20)\end{array}$ & $\begin{array}{c}25.00 \\
(30.00)\end{array}$ & $\begin{array}{c}13.00 \\
(20.00)\end{array}$ & $\begin{array}{c}4.00 \\
(0.00)\end{array}$ & $\begin{array}{c}17.00 \\
(20.00)\end{array}$ & 90 & 340 & 70 \\
\hline $\mathrm{L}: \mathrm{jv}$ & 10 & 6 & 30.00 & 15.00 & 0.00 & 15.00 & 90 & 355 & 265 \\
\hline $\mathrm{L}: \mathrm{hv}$ & 9 & 6 & 27.00 & 15.00 & 0.00 & 15.00 & 90 & 334 & 244 \\
\hline L: ce & 12 & 6 & 36.00 & 15.00 & 0.00 & 15.00 & 90 & 320 & 230 \\
\hline BB: NW & 16 & 12 & 16.00 & 12.00 & 2.00 & 14.00 & 90 & 320 & 230 \\
\hline BB: NE & 16 & 12 & 16.00 & 12.00 & 2.00 & 14.00 & 90 & 230 & 140 \\
\hline $\mathrm{N}-\mathrm{W}$ & 14 & 14 & 18.00 & 24.00 & 5.00 & 20.43 & 40 & 122 & 212 \\
\hline N-DR & 29 & $\begin{array}{c}31 \\
(40)\end{array}$ & 29.00 & $\begin{array}{c}31.00 \\
(40.00)\end{array}$ & $\begin{array}{c}5.23 \\
(1.95)\end{array}$ & $\begin{array}{c}25.57 \\
(28.19)\end{array}$ & 41 & 109.6 & 199.6 \\
\hline N-HU & 1 & 1 & 10.51 & 13.28 & 5.72 & 14.43 & 40.96 & 109.6 & 199.6 \\
\hline $\mathrm{N}-\mathrm{HV}$ & 10 & 13 & 20.00 & 26.00 & 1.00 & 18.06 & 41 & 109.6 & 199.6 \\
\hline N-S: 1a & 14 & 5 & 30.00 & 10.70 & 0.00 & 9.07 & 58 & 122 & 212 \\
\hline $\mathrm{N}-\mathrm{S}: 1 \mathrm{~b}$ & 14 & 9 & 30.00 & 19.30 & 9.07 & 20.95 & 38 & 122 & 212 \\
\hline N-S: 2 & 6 & 5 & 12.90 & 10.70 & 0.00 & 8.51 & 52.7 & 119.3 & 29.3 \\
\hline $\mathrm{AN}$ & $\begin{array}{c}25 \\
(45)\end{array}$ & $\begin{array}{c}17 \\
(25)\end{array}$ & $\begin{array}{c}25.00 \\
(45)\end{array}$ & $\begin{array}{c}17.00 \\
(25.00)\end{array}$ & $\begin{array}{c}5.45 \\
(0.20)\end{array}$ & $\begin{array}{c}16.60 \\
(16.60)\end{array}$ & 41 & 109.6 & 199.6 \\
\hline HM-J: $11 \mathrm{~m}$ & 11 & 6 & 33.00 & 16.20 & 0.28 & 16.41 & 85 & 346 & 76 \\
\hline HM-J: 1lw & 7 & 6 & 21.00 & 15.40 & 0.26 & 15.14 & 75 & 322 & 52 \\
\hline HM-J: b & 10 & 6 & 30.00 & 16.20 & 0.27 & 16.41 & 85 & 325 & 55 \\
\hline HM-K: 11 & 15 & 12 & 30.00 & 24.00 & 0.15 & 23.54 & 77 & 325 & 55 \\
\hline HM-K: b & 23 & 12 & 46.00 & 24.00 & 0.15 & 23.54 & 77 & 345 & 75 \\
\hline
\end{tabular}

Slip-model letter designations refer to the referenced finite-source models of Table A1. Some finite-source models have multiple rupture planes: UP: main, upland main rupture plane; UP: asp. Upland large asperity off main plane; L: jv, hv, and ce, Johnson Valley, Homestead Valley, and Camprock/ Emerson segments; BB: NW and NE, northwest- and northeast-oriented planes for the Big Bear model; N-S: 1a, 1b, and 2, north-south model plane 1 upper part (steeper dip), lower part (shallower dip), and second plane, respectively; HM-J: 1lm, llw, and b, Lavic Lake middle, Lavic Lake west, and Bullion fault segments; HM-K: 11 and b, Lavic Lake and Bullion fault segments. Numbers in parentheses show the rupture model dimensions if you include rows or columns with zero slip.

model hypocenter is considered, the percent of moment release of background seismicity shallower than the bottom of the slip-model rupture plane is $99.3 \%$, which is consistent with the other reference models. For the hypocenter test, however, considering only the background seismicity to the northeast of the NPS mainshock hypocenter, the percent of hypocenters shallower than the bottom of the slip model rupture plane is $86 \%$, still inconsistent with the rest of the models. Because of the complexity of the mainshock region around the NPS earthquake, we have excluded model NPS from our calculation of the appropriate value of percent for the prediction of seismogenic thickness.

The other excluded model, model N-HU, is a constantslip, finite-source model based only on geodetic data, and the bottom of the slip model is 3.6 to $6.0 \mathrm{~km}$ shallower than that in the four other models of the Northridge mainshock. The bottom of the slip model is shallower even than the hypocenter of the earthquake at $18.7 \mathrm{~km}$ (Hauksson et al., 1995). We therefore exclude the N-HU model from our calculation of the appropriate value of percent for the prediction of seismogenic thickness in southern California.

Smallest Allowable Step in the Percentage for the Hypocenter Distribution Test

Unlike the moment release distribution, the hypocenter of the large earthquake counts the same as a small-magnitude earthquake for the hypocenter calculation. This can lead to either underprediction or overprediction of the seismogenic thickness, depending on the depths and magnitudes of the earthquakes. Overprediction is usually the result of rounding in the hypocenter prediction calculation such that the deepest earthquake in the regional bin is chosen for the percent depth. In other words, the percentage of the earthquakes in the regional bin that is closest to the wanted percent of $98.3 \%$ 
Table A3

Finite-Source Model Trimmed Rupture Dimensions

\begin{tabular}{|c|c|c|c|c|c|c|c|c|c|c|c|c|}
\hline Slip Model & $\mathrm{L}$ & $\mathrm{R}$ & $\mathrm{T}$ & B & Columns & Rows & Length $(\mathrm{km})$ & Width (km) & Top (km) & Bottom $(\mathrm{km})$ & Moment $(\mathrm{N} \mathrm{m})$ & Percent of Original \\
\hline NPS* & & 1 & & 1 & 10 & 7 & 20.00 & 13.30 & 4.00 & 13.57 & $1.68 \mathrm{E}+18$ & 94.6 \\
\hline $\mathrm{WN}^{*}$ & & & & & 10 & 10 & 10.00 & 10.00 & 12.00 & 17.00 & $9.45 \mathrm{E}+17$ & 100.0 \\
\hline ER* & & 2 & 1 & & 8 & 4 & 20.00 & 8.00 & 2.00 & 10.00 & $2.25 \mathrm{E}+18$ & 97.5 \\
\hline $\mathrm{SH}-\mathrm{W}^{*}$ & & 1 & 3 & & 19 & 7 & 19.00 & 8.05 & 3.95 & 12.00 & $4.41 \mathrm{E}+18$ & 91.7 \\
\hline SH-L & & & & & 10 & 5 & 25.00 & 10.00 & 0.00 & 10.00 & $9.76 \mathrm{E}+18$ & 100.0 \\
\hline UP* & & & & & & & & & & & $2.51 \mathrm{E}+17$ & 100.0 \\
\hline UP: main & & & & & 2 & 2 & 3.50 & 3.50 & 6.00 & 9.36 & $1.76 \mathrm{E}+17$ & 100.0 \\
\hline UP: asp. & & & & & 1 & 1 & 1.00 & 1.00 & 8.00 & 9.00 & $7.49 \mathrm{E}+16$ & 100.0 \\
\hline $\mathrm{SM}^{*}$ & $\begin{array}{c}1 \\
\text { (4) }\end{array}$ & & 2 & 2 & 6 & 6 & 4.20 & 3.60 & 10.47 & 13.08 & $2.68 \mathrm{E}+17$ & 94.4 \\
\hline JT-B & $\begin{array}{l}4 \\
\text { (7) }\end{array}$ & $\begin{array}{c}12 \\
(15)\end{array}$ & 3 & 2 & 13 & 15 & 13.00 & 15.00 & 0.00 & 18.00 & $1.52 \mathrm{E}+18$ & 89.8 \\
\hline JT-HD* & 15 & $\begin{array}{c}3 \\
(8)\end{array}$ & $\begin{array}{c}1 \\
(5)\end{array}$ & $\begin{array}{c}2 \\
(5)\end{array}$ & 7 & 10 & 7.00 & 10.00 & 5.00 & 15.00 & $1.34 \mathrm{E}+18$ & 92.1 \\
\hline $\mathrm{L}^{*}$ & & & & & & & & & & & $7.68 \mathrm{E}+19$ & 99.3 \\
\hline $\mathrm{L}: \mathrm{jv}$ & & 2 & & & 8 & 6 & 24.00 & 15.00 & 0.00 & 15.00 & $1.93 \mathrm{E}+19$ & 97.9 \\
\hline $\mathrm{L}: \mathrm{hv}$ & & & & & 9 & 6 & 27.00 & 15.00 & 0.00 & 15.00 & $3.72 \mathrm{E}+19$ & 100.0 \\
\hline $\mathrm{L}: \mathrm{ce}$ & 1 & & & & 11 & 6 & 33.00 & 15.00 & 0.00 & 15.00 & $2.04 \mathrm{E}+19$ & 99.2 \\
\hline $\mathrm{BB}^{*}$ & & & & & & & & & & & $5.53 \mathrm{E}+18$ & 100.0 \\
\hline BB: NW & & & & & 16 & 12 & 16.00 & 12.00 & 2.00 & 14.00 & $2.65 \mathrm{E}+18$ & 100.0 \\
\hline BB: NE & & & & & 16 & 12 & 16.00 & 12.00 & 2.00 & 14.00 & $2.88 \mathrm{E}+18$ & 100.0 \\
\hline $\mathrm{N}-\mathrm{W}^{*}$ & & & 1 & & 14 & 13 & 18.00 & 22.29 & 6.10 & 20.43 & $1.37 \mathrm{E}+19$ & 98.3 \\
\hline N-DR & 8 & 7 & $\begin{array}{c}1 \\
(6)\end{array}$ & $\begin{array}{c}8 \\
\text { (12) }\end{array}$ & 14 & 22 & 14.00 & 22.00 & 5.89 & 20.32 & $1.05 \mathrm{E}+19$ & 88.3 \\
\hline N-HU & & & & & 1 & 1 & 10.51 & 13.28 & 5.72 & 14.43 & $1.05 E+19$ & 100.0 \\
\hline N-HV & & & & & 10 & 13 & 20.00 & 26.00 & 1.00 & 18.06 & $1.63 \mathrm{E}+19$ & 100.0 \\
\hline $\mathrm{N}-\mathrm{S}$ & & & & & & & & & & & $1.49 \mathrm{E}+19$ & 96.8 \\
\hline N-S: 1a & 1 & & & & 13 & 5 & 27.86 & 10.70 & 0.00 & 9.07 & $3.27 \mathrm{E}+18$ & 95.3 \\
\hline N-S: $1 b$ & 1 & & & 1 & 13 & 8 & 27.86 & 17.16 & 9.07 & 19.63 & $9.53 \mathrm{E}+18$ & 96.7 \\
\hline N-S: 2 & & & & & 6 & 5 & 12.90 & 10.70 & 0.00 & 8.51 & $1.90 \mathrm{E}+18$ & 100.0 \\
\hline $\mathrm{AN}^{*}$ & $\begin{array}{c}7 \\
\text { (17) }\end{array}$ & $\begin{array}{c}4 \\
(14)\end{array}$ & $\begin{array}{c}1 \\
(9)\end{array}$ & 4 & 14 & 12 & 14.00 & 12.00 & 6.10 & 13.98 & $9.48 \mathrm{E}+17$ & 93.4 \\
\hline HM-J* & & & & & & & & & & & $5.93 E+19$ & 95.9 \\
\hline HM-J: $11 \mathrm{~m}$ & & 1 & & 1 & 10 & 5 & 30.00 & 13.50 & 0.28 & 13.72 & $2.61 \mathrm{E}+19$ & 97.5 \\
\hline HM-J: $11 \mathrm{w}$ & 1 & & & 1 & 6 & 5 & 18.00 & 12.83 & 0.26 & 12.66 & $2.08 \mathrm{E}+19$ & 92.9 \\
\hline HM-J: b & 1 & & & 2 & 9 & 4 & 27.00 & 10.80 & 0.27 & 11.28 & $1.25 \mathrm{E}+19$ & 97.6 \\
\hline HM-K & & & & & & & & & & & $5.47 \mathrm{E}+19$ & 81.5 \\
\hline HM-K: 11 & & 6 & & 4 & 9 & 8 & 18.00 & 16.00 & 0.15 & 15.74 & $2.48 \mathrm{E}+19$ & 86.3 \\
\hline HM-K: b & & & & 4 & 23 & 8 & 46.00 & 16.00 & 0.15 & 15.74 & $2.02 E+19$ & 78.8 \\
\hline HM-K: sb & & & & 4 & 15 & 8 & 30.00 & 16.00 & 0.15 & 15.74 & $9.67 \mathrm{E}+18$ & 75.8 \\
\hline
\end{tabular}

This table shows the results of the trimming process. L, R, T, and B refer to the number of rows or columns trimmed from the published slip model from the left, right, top, and bottom, respectively. Numbers in parentheses show the number of trimmed rows or columns if you count rows or columns in the untrimmed rupture model with zero slip. The trimmed rupture model used in this study has the length and width, top and bottom depths, and seismic moment shown in the table.

*, the 12 models used to represent the moment release of the earthquakes for the prediction phase of the study.

is $100 \%$. This suggests that at least 30 earthquakes are needed within a regional bin in order to make the hypocenter seismogenic thickness prediction reasonable and reliable (each hypocenter accounts for 3.3\% of the total and 29 hypocenters account for $96.7 \%$ of the total, which is closer to $98.3 \%$ than $100 \%$ is). It is important to determine the depth down to which most of the hypocenters occur (the definition of percent depth), rather than the depth that includes all of them. Underprediction occurs when one or a few earthquakes dominate the moment release depth distribution of the regional bin. The hypocenter is not indicative of the depth extent of rupture of a larger earthquake, nor the amount of brittle fracture accomplished by a single earthquake. These situations show how important it is to examine the moment release depth distribution of earthquakes, rather than treating all hypocenters the same, regardless of earthquake magnitude.

\section{Errors in Using Seismic Moment Release to Predict} the Seismogenic Thickness

To evaluate the effect of the potential mislocation in the depth of the hypocenter (vertical error) and the uncertainty in the distribution of the moment release about the hypocenter, we consider their effects on the extremes in distributing 
the moment release. The moment release distribution extremes are simply the extremes in the moment release distribution that result from combining these two major sources of uncertainty for every earthquake within a regional bin. One extreme shallows the moment distribution by subtracting the vertical error from the hypocenter depth (depth positive) and by assuming the earthquake ruptures up from the hypocenter (moment is distributed above the hypocenter). This shallow extreme puts more moment higher in the crust and reduces the maximum depth of seismic rupture.

The other extreme deepens the moment distribution by adding the vertical error to the hypocenter depth and assuming the plane ruptures down from the hypocenter (moment is distributed below the hypocenter). Thus, the deep extreme puts more moment deeper in the crust and increases the maximum depth of seismic rupture. Although it is highly unlikely that either extreme of moment distribution with depth actually occurs for all earthquakes within a region, the extremes allow us to place reasonable error bounds on our results.

\section{Acknowledgments}

We thank R. Clayton and N. Field for interest in this project and important discussions, and Jeanne Hardebeck, Harold Magistrale, and Keith Richards-Dinger for reviewing the manuscript. Their comments greatly improved the manuscript. The figures were done using GMT (Wessel and Smith, 1991). This work was supported by U.S. Geological Survey Grants 01HQGR038 and 02HQGR0044 to Caltech and by grants from the Southern California Earthquake Center. SCEC is funded by National Science Foundation Cooperative Agreement EAR-0106924 and USGS Cooperative Agreement 02HQAG0008. This article is SCEC contribution no. 753. It is contribution 9031, Division of Geological and Planetary Sciences, California Institute of Technology, Pasadena, California

\section{References}

Bennett, R. A., R. E. Reilinger, W. Rodi, Y. Li, M. N. Toksoz, and K. Hudnut (1995). Coseismic slip associated with the $1992 M_{\mathrm{w}} 6.1$ Joshua Tree, California, earthquake: implications for the Joshua TreeLanders earthquake sequence, J. Geophys. Res. 100, 6443-6461.

Doser, D. I., and H. Kanamori (1986). Depth of seismicity in the Imperial Valley region (1977-1983) and its relationship to heat flow, crustal structure, and the October 15, 1979, earthquake, J. Geophys. Res. 91, 675-688.

Dreger, D. (1997). The large aftershocks of the Northridge earthquake and their relationship to mainshock slip and fault zone complexity, Bull. Seism. Soc. Am. 87, 1259-1266.

Dreger, D. S. (1994). Empirical Green's Function study of the January 17, 1994, Northridge, California, earthquake, Geophys. Res. Lett. 21, 2633-2636.

Dreger, D. S., and D. V. Helmberger (1991). Complex faulting deduced from broadband modeling of the 28, February 1990 Upland earthquake $\left(M_{\mathrm{L}}=5.2\right)$, Bull. Seism. Soc. Am. 81, 1129-1144.

Field, E. H., D. D. Jackson, and J. F. Dolan (1999). A mutually consistent seismic-hazard source model for southern California, Bull. Seism. Soc. Am. 89, 559-578.

Gurrola, L. D., and T. Rockwell (1996). Timing and slip for prehistoric earthquakes on the Superstition Mountain Fault, Imperial Valley, southern California, J. Geophys. Res. 101, 5977-5985.

Hanks, T. C., and H. Kanamori (1979). A moment magnitude scale, $J$. Geophys. Res. 84, 2348-2350.
Hartzell, S. (1989). Comparison of seismic waveform inversion results for the rupture history of a finite fault: application to the 1986 North Palm Springs, California, earthquake, J. Geophys. Res. 94, 7515-7534.

Hartzell, S., and M. Iida (1990). Source complexity of the 1987 Whittier Narrows, California, earthquake from the inversion of strong ground motion records, J. Geophys. Res. 95, 12,475-12,485.

Hauksson, E. (2000). Crustal structure and seismicity distribution adjacent to the Pacific and North American plate boundary in southern California, J. Geophys. Res. 105, 13,875-13,903.

Hauksson, E., L. M. Jones, and K. Hutton (1995). The 1994 Northridge earthquake sequence in California: seismological and tectonic aspects, J. Geophys. Res. 100, 12,335-12,355.

Hill, D. P., J. P. Eaton, and L. M. Jones (1990). Seismicity, 1980-86, in The San Andreas Fault System, California, U.S. Geol. Surv. Profess. Pap. 1515, 115-152.

Hough, S. E., and D. S. Dreger (1995). Source parameters of the April 23, 1992, M 6.1 Joshua Tree, California, earthquake and its aftershocks: empirical Green's function analysis of GEOS and TERRAscope data, Bull. Seism. Soc. Am. 85, 1576-1590.

Hudnut, K. W., Z. Shen, M. Murray, S. McClusky, R. King, T. Herring, B. Hager, Y. Feng, P. Fang, A. Donnellan, and Y. Bock (1996). CoSeismic displacements of the 1994 Northridge, California, earthquake, Bull. Seism. Soc. Am. 86, S19-S36.

Jennings, P. (1975). Fault map of California with volcanoes, thermal springs and thermal wells, 1:750.000 scale, Geological Data Map 1, California Division of Mines and Geology, Sacramento, California.

Ji, C., D. J. Wald, and D. V. Helmberger (2002). Source description of the 1999 Hector Mine, California earthquake. Part II. Complexity of slip history, Bull. Seism. Soc. Am. 92, 1208-1226.

Jones, L. E., and S. E. Hough (1995). Analysis of broadband records from the 28 June 1992 Big Bear earthquake: evidence of a multiple-event source, Bull. Seism. Soc. Am. 85, 688-704.

Kaverina, A., D. Dreger, and E. Price (2002). The combined inversion of seismic and geodetic data for the source process of the 16 October $1999 M_{\mathrm{W}} 7.1$ Hector mine, California, earthquake, Bull. Seism. Soc. Am. 92, 1266-1280.

Larsen, S., R. Reilinger, H. Neugebauer, and W. Strange (1992). Global Positioning System measurements of deformations associated with the 1987 Superstition Hills earthquake: evidence for conjugate faulting, J. Geophys. Res. 97, 4885-4902.

Magistrale, H., and T. Rockwell (1996). The Central and Southern Elsinore Fault Zone, Southern California, Bull. Seism. Soc. Am. 86, 1793 1803.

Magistrale, H., and C. Sanders (1996). Evidence from precise earthquake hypocenters for segmentation of the San Andreas fault in San Gorgonio Pass, J. Geophys. Res. 101, 3031-3044.

Magistrale, H., and H. Zhou (1996). Lithologic control of the depth of earthquakes in southern California, Science 273, 639-642.

Mai, P. M., and G. C. Beroza (2000). Source scaling properties from finitefault-rupture models, Bull. Seism. Soc. Am. 90, 604-615.

Miller, C. K., and K. P. Furlong (1988). Thermal-mechanical controls on seismicity depth distributions in the San Andreas fault zone, Geophys. Res. Lett. 15, 1429-1432.

Peterson, M. D., W. A. Bryant, C. H. Cramer, T. Cao, M. S. Reichle, A. D. Frankel, J. J. Lienkaemper, P. A. McCrory, and D. P. Schwartz (1996). Probablistic seismic hazard assessment for the state of California, U.S. Geol. Surv. Open-File Rept. 96-0706.

Rockwell, T. K., C. Loughman, and P. Merifeld (1990). Late Quaternary rate of slip along the San Jacinto fault zone near Anza, southern California, J. Geophys. Res. 86, 8593-8605.

Sanders, C. O. (1987). Seismotectonics of the San Jacinto fault zone and the Anza seismic gap, Ph.D. thesis, California Institute of Technology, Pasadena, California.

Sanders, C. O. (1990). Earthquake depths and the relation to strain accumulation and stress near strike-slip faults in southern California, $J$. Geophys. Res. 95, 4751-4762.

Shen, Z., B. X. Ge, D. D. Jackson, D. Potter, M. Cline, and L. Sung (1996). 
Northridge earthquake rupture models based on the Global Positioning System measurements, Bull. Seism. Soc. Am. 86, S37-S48.

Sibson, R. H. (1982). Fault zone models, heat flow, and the depth distribution of earthquakes in the continental crust of the United States, Bull. Seism. Soc. Am. 72, 151-163.

Somerville, P., K. Irikura, R. Graves, S. Sawada, D. Wald, N. Abrahamson, Y. Iwasaki, T. Kagawa, N. Smith, and A. Kowada (1999). Characterizing crustal earthquake slip models for the prediction of strong ground motion, Seism. Res. Lett. 70, 59-80.

Vaughan, P. R., K. M. Thorup, and T. K. Rockwell (1999). Paleoseismology of the Elsinore Fault at Agua Tibia Mountain, Southern California, Bull. Seism. Soc. Am. 89, 1447-1457.

Wald, D. J. (1992). Strong motion and broadband teleseismic analysis of the 1991 Sierra Madre, California, earthquake, J. Geophys. Res. 97, 11,033-11,046.

Wald, D. J., and T. H. Heaton (1994). Spatial and temporal distribution of slip for the 1992 Landers, California earthquake, Bull. Seism. Soc. Am. 84, 668-691.

Wald, D. J., T. H. Heaton, and K. W. Hudnut (1996). The slip history of the 1994 Northridge California, earthquake determined from strong ground motion, teleseismic, GPS, and leveling data, Bull. Seism. Soc. Am. 86, S49-S70.
Wald, D. J., D. V. Helmberger, and S. H. Hartzell (1990). Rupture process of the 1987 Superstition Hills earthquake from the inversion of strongmotion data, Bull. Seism. Soc. Am. 80, 1079-1098.

Wells, D. L., and K. J. Coppersmith (1994). New empirical relationships among magnitude, rupture length, rupture width, rupture area, and surface displacement, Bull. Seism. Soc. Am. 84, 974-1002.

Wessel, P., and W. H. F. Smith (1991). Free software helps map and display data, Eos Trans. AGU 72, 441, 445-446.

Williams, C. F. (1996). Temperature and the seismic/aseismic transition: observations from the 1992 Landers earthquake, Geophys. Res Lett. 23, 2029-2032.

Working Group on California Earthquake Probabilities (1995). Seismic hazards in southern California: probable earthquakes, 1994 to 2024, Bull. Seism. Soc. Am. 85, 379-439.

Working Group on California Earthquake Probabilities (1988). Probabilities of large earthquakes occurring in California on the San Andreas fault, U.S. Geol. Survey Open-File Rept. 88-398.

Seismological Laboratory

California Institute of Technology

Pasadena, California 91125

Manuscript received 17 June 2002. 